Caroline Krafft ${ }^{1, *}$ and Ragui Assaad ${ }^{2}$

\title{
Introducing the Jordan Labor Market Panel Survey 2016
}

\begin{abstract}
This paper introduces the 2016 wave of the Jordan Labor Market Panel Survey (JLMPS). It is an essential reference for users of this innovative and valuable dataset, which adds to the growing series of labor market panel surveys (LMPSs) produced by the Economic Research Forum (ERF). The 2016 wave is a follow-up on the initial 2010 wave. There has been substantial turmoil in the region since 2010, including the onset of the Syrian conflict and the influx of refugees into Jordan. The 2016 wave over-sampled areas with a high proportion of non-Jordanians to be able to represent and examine this important population. The paper describes this sampling strategy, attrition from 2010 to 2016, and weighting that corrects for attrition and accounts for the sampling strategy. We compare key demographic measures and labor market statistics with other sources of data on Jordan to demonstrate the sample's representativeness. The data provide an important opportunity for a detailed analysis of Jordan's changing labor market and society.
\end{abstract}

Current version:

Keywords:

JEL codes:

Corresponding author:
June 07, 2021

survey data, public use data, sample weights, labor, refugees, Jordan J00, C81, C83

Caroline Krafft

cgkrafft@stkate.edu

1 Department of Economics and Political Science, St. Catherine University, Saint Paul, MN 55105, USA

2 Humphrey School of Public Affairs, University of Minnesota, Minneapolis, MN 55455, USA

(c) The Author(s). 2021. Open Access This article is distributed under the terms of the Creative Commons Attribution 4.0 International License (http://creativecommons.org/licenses/by/4.0/), which permits unrestricted use, distribution, and reproduction in any medium, provided you give appropriate credit to the original author(s) and the source, provide a link to the Creative Commons license, and indicate if changes were made. __ Cite as: Krafft and Assaad. IZA Journal of Development and Migration (2021) 12:08 


\section{Introduction}

In the period between 2010 and 2016, Jordan was buffeted by large external shocks resulting from the eruption of the Arab Spring uprisings in late 2010 and 2011 and the subsequent conflicts in two of Jordan's neighbors, Syria and Iraq. Although some of the macroeconomic effects of these shocks and their impacts on specific sectors of the Jordanian economy have been studied (Al-Amaera, 2019; Arayssi et al., 2019; Magablih and Mustafa, 2018), their broader effects on Jordanian society have not been fully investigated, due to the limited availability of nationally representative survey data. As part of its series of comprehensive labor market panel surveys (LMPSs), the Economic Research Forum (ERF) had conducted a survey in Jordan in 2010, the Jordan Labor Market Panel Survey of 2010 (JLMPS 2010), and had planned to conduct a new wave after 6 years. The JLMPS 2016, which is the subject of this paper, thus comes at an opportune time to allow for an in-depth assessment of critical social and economic developments in Jordan's recent history.

The purpose of this paper is to introduce the JLMPS 2016 dataset to the research community. This paper documents changes in the questionnaire design and explains the sampling strategy designed to capture the large influx of new refugee and migrant populations to Jordan since the previous wave of the survey in 2010. The paper also analyzes the two types of attrition that can occur from the sample previously interviewed in 2010, and computes panel weights that correct for attrition. The first type of attrition involves households interviewed in 2010 that could not be located in 2016 and the second type involves individuals who split from these households in the intervening period, who could not be located in 2016. In addition, the paper provides a comparison of basic demographic and labor market variables between the JLMPS and other Jordanian data sources such as the Employment and Unemployment Survey (EUS) and the Population Census. It also compares retrospective data from the 2016 wave with contemporaneous data from the 2010 wave for the same individuals to assess the reliability of the retrospective data collection methods used in the JLMPS.

The JLMPS is a part of a series of LMPSs carried out by the ERF in several Arab countries since 1998, and its microdata are available for public use through the ERF data portal. ${ }^{1}$ These surveys have, so far, been carried out in Egypt (1998, 2006, 2012, and 2018), Jordan (2010 and 2016), and Tunisia (2014), with future waves in the planning stages. ${ }^{2}$ The ERF LMPSs are carried out in cooperation with the national statistical office of each country. Accordingly, the JLMPS 2016 was carried out in cooperation with the Jordanian Department of Statistics (DoS), which had preserved the personally identifiable information (PII) of the sample from the previous wave, supplied a refresher sample based on the design provided by ERF researchers, and implemented all data collection activities using tablet computers. ${ }^{3}$

ERF's LMPSs not only generate all the usual labor market statistics obtained from the standard labor force surveys, but also provide a rich basis for an extensive research agenda on labor markets and human development in some key Middle East and North Africa (MENA)

www.erfdataportal.com

2 See Krafft et al. (2019) for more information on ELMPS 2018, Assaad et al. (2016) for more information on TLMPS 2014, Assaad and Krafft (2013) for more information on ELMPS 2012, Assaad (2014) for more information on JLMPS 2010, Assaad and Roushdy (2009) for more information on ELMPS 2006, and Assaad and Barsoum (2000) for more information on ELMPS 1998.

3 The questionnaire was programmed using the Askia CAPI software by programmers from Forcier Consulting (www. forcierconsulting.com). 
countries, much of which could not have been possible without these surveys. Not only are the LMPSs longitudinal in the sense that they follow an existing population over time, every 6 years or so, but they also contain detailed retrospective questions allowing for studying interdependencies among phenomena that take place over the life course. For example, the LMPSs have detailed modules examining residential mobility and migration, educational, marital, fertility, and job market histories. They have already spawned an extensive body of research on schooling patterns and outcomes (Assaad and Krafft, 2015; Assaad and Saleh, 2018; Elbadawy, 2015; Hailat, 2019), school-to-work transitions and labor market insertion of youth (Amer, 2014, 2019; Amer and Atallah, 2019; Assaad, 2008; Assaad and Krafft, 2021; Gebel and Heyne, 2016), household formation and fertility patterns (Assaad et al., 2010; Assaad et al., 2017; Friedrich et al., 2020; Krafft, 2020; Krafft and Assaad, 2020; Selwaness and Krafft, 2021; Sieverding et al., 2020; Sieverding et al., 2019), migration (Malaeb and Wahba, 2019; Wahba, 2015), wage formation and patterns of inequality (El-Hamidi and Said, 2014; Krafft et al., 2021; Said, 2015; Salehi-Isfahani et al., 2009), barriers to women's employment (Assaad et al., 2020; Assaad et al., 2014; Hendy, 2015), and many other topics.

There has been a great deal of concern about the situation of Syrian refugees in Jordan and the impact of the Syrian influx on Jordanian society (Alrababa'h et al., 2021; Lenner and Turner, 2019; Maystadt et al., 2019; UNHCR, 2018). The 2010 wave of the JLMPS was implemented just prior to the Arab Spring and the subsequent conflicts in the region. Although Jordan itself did not have internal conflict, its neighbors, Iraq and Syria, did, resulting in a large flow of refugees into Jordan. Based on the Jordanian Population Census of 2015, there were 9.5 million individuals in Jordan, of whom 6.6 million were Jordanian and 1.3 million were Syrian (Department of Statistics (Jordan), 2015a, 2015b). UNHCR's estimate of the number of registered Syrian refugees in Jordan as of September 2017 was 654,000 (UNHCR, 2017). In addition, Jordan hosts a large population of migrant workers, including 636,000 Egyptians as of 2015 (Department of Statistics (Jordan), 2015b). Jordan also hosts a number of Palestinians, with substantial waves of arrivals around 1948 and 1967 (Turner, 2016). Individuals of Palestinian origin originating from the West Bank are Jordanian citizens and therefore counted in the Jordanian population. However, non-nationalized Palestinians were the third largest group after Syrians and Egyptians in Jordan, at around 634,000 individuals in 2015 (Department of Statistics (Jordan), 2015b). They are made up of Palestinians from Gaza as well as recent arrivals who had previously been Palestinian refugees in Syria. There were also around 131,000 Iraqis and smaller numbers from numerous other countries. Altogether, these non-Jordanians play a large and increasing role in the Jordanian economy (Assaad and Salemi, 2019).

The 2016 wave of the JLMPS was designed to capture the implications of the large influx of both refugee and migrant worker flows into Jordan in recent years. To this end, the survey design team decided to add a large refresher sample of 3,000 households that over-sampled neighborhoods in Jordan that had high proportions of non-Jordanian households, including refugee camps, as ascertained by the 2015 Population Census. New modules were also added to the questionnaire to inquire about the in-migration of non-Jordanians, food security, and household exposure to shocks and coping strategies. We assumed that the 2015 Population Census counts of various nationality groups are appropriate for our sample and reproduce these counts by means of the appropriate ex-post weights. This makes the 2016 wave of the JLMPS unique in its ability to both examine the effects of the influx of refugees on Jordanian 
society (Al-Hawarin et al., 2021; Assaad et al., 2018; Fallah et al., 2019; Malaeb and Wahba, 2018), and the living and livelihood conditions of refugees in Jordan (Krafft, Razzaz, et al., 2019; Krafft, Sieverding, et al., 2019). As far as we are aware, JLMPS 2016 is the only source of publicly available microdata on the labor market conditions facing Syrians and other non-nationals in Jordan.

This paper describes JLMPS 2016, starting with the sample overview, questionnaires, and data availability in Section 2. Section 3 discusses data collection and fielding, the initial 2010 and 2016 refresher samples, describes attrition from 2010 to 2016, and details the resulting 2016 sample. Section 4 presents models of attrition from 2010 to 2016 , as well as weighting that corrects for attrition and accounts for the sampling strategy. We compare key demographic measures and labor market statistics with other sources of data on Jordan to demonstrate the sample's representativeness in Section 5. We also demonstrate how improvements in the design of the questionnaires increased the accuracy of our data in Section 6. Section 7 concludes, noting the limitations of the data but that the data provide an important opportunity for detailed analysis of Jordan's changing labor market and society.

\section{Sample overview, questionnaires, and data availability}

\subsection{Sample overview}

As the second wave of the JLMPS longitudinal study, JLMPS 2016 both followed the 2010 panel and added a refresher sample. For the panel component of the data, we attempted to recontact all households that were included in the 2010 wave. Among the households that were found, we also followed any split households. Split households occur when one or more individuals from 2010 leave their 2010 household to form a new household. For example, an individual who was the son of the household head in 2010 might marry and form a new household. The entire new household is included in our sample, including members who were not a part of the 2010 sample. The refresher sample over-sampled neighborhoods in Jordan that, as of the 2015 Census, had a high proportion of non-Jordanians. The sample weights account for this sampling strategy to generate nationally representative statistics, allowing for analyses not only by nationality but also for the Jordanian labor market overall (Assaad et al., 2019; Assaad and Salemi, 2019; Krafft et al., 2019; Malaeb and Wahba, 2019). The final JLMPS 2016 sample is made up of 7,229 households, including 3,058 that were part of the original 2010 sample, 1,221 split households, and 2,950 refresher households. The JLMPS 2016 sample captured a total of 33,450 individuals. We discuss the sampling strategy and the creation of the sampling and attrition weights in detail below.

\subsection{The questionnaires}

The questionnaires for JLMPS 2016 build on those used in 2010, as indicated in Table 1. The questionnaires include a household questionnaire, an individual questionnaire, and a questionnaire administered at the household level that elicits information about household enterprises and current migrants and remittances. The household questionnaire includes the identifying information for the household, a household roster and information on housing conditions, access to public services, ownership of durable goods, and use of household help. The individual questionnaire includes (i) a personal biography, which elicits information about marriage history, 
Table 1 Modules of the questionnaire in 2010 and 2016

\begin{tabular}{ll}
\hline Modules present in $\mathbf{2 0 1 0}$ & Modules added in $\mathbf{2 0 1 6}$ \\
\hline Household questionnaire & \\
- Household identifying information, roster & \\
- Housing and durable goods & \\
Individual questionnaire & Individual questionnaire \\
- Father's characteristics, mother's & - Personal biography (life history) \\
characteristics, siblings' characteristics & - Health \\
- Education & - In-migration (non-Jordanians) \\
- Employment and unemployment & - Information technology \\
- Subsistence and domestic work & - Savings and borrowing \\
- Characteristics of the primary job and wages & - Gender attitudes \\
- Secondary jobs and wages & \\
- Labor market history & \\
- Birth history & \\
- Women's decision-making, mobility, and & \\
- Cocceptability of intimate partner violence & \\
- Women's employment, maternity leave, and & \\
- Return migration & \\
Enterprise questionnaire & \\
- Remittances/transfers, other income sources & - Current migrants \\
- Household non-farm enterprises and & Household non-farm enterprise \\
\hline & expenditures, assets, and revenues \\
\hline &
\end{tabular}

Source: Authors' construction based on JLMPS 2010 and JLMPS 2016 questionnaires.

JLMPS, Jordan Labor Market Panel Survey.

entry and exit from school, start and end of jobs, and residential mobility, (ii) modules on father's, mother's, and siblings' characteristics, (iii) self-reported health, health insurance, and health-seeking behavior, (iv) educational status and detailed educational history, (v) employment in the short (1 week) and long (3 months) reference periods, including keyword questions to detect employment as defined by the 19th International Conference of Labour Statisticians, (vi) unemployment and job search, (vii) subsistence and domestic work, (viii) detailed characteristics of the primary job, (ix) characteristics of the secondary job, (x) labor market history, (xi) fertility, (xii) women's decision-making, mobility, and acceptability of intimate partner violence, (xiii) costs and characteristics of marriage, (xiv) women's employment, maternity leave, and childcare, (xv) wage earnings in primary and secondary jobs, (xvi) return migration, (xvii) in-migration for non-Jordanians, (xviii) use of information technology, (xix) savings and borrowing behavior, and $(\mathrm{xx})$ gender attitudes. The current migration and household enterprise questionnaire elicits information about (i) current migrants abroad, (ii) remittances, (iii) sources of non-labor income, (iv) household non-farm enterprises, including sections on hired labor, expenditures, assets, and revenues, ${ }^{4}$ and (v) agricultural landholding, livestock, capital assets, revenue from crop production, and other sources of agricultural income. Note that additional questions on food security were added to the health module to ascertain household

4 Due to problems in the implementation of appropriate screening questions and skip patterns, a non-representative sub-sample of the self-employed and employers was captured; the resulting data will not be publicly released. 
vulnerability to shocks. We also substantially revised the labor market history modules in light of the lessons learned from research that compared the reliability of retrospective data from the LMPSs to that of panel data (Assaad et al., 2018). The revisions, described in detail and analyzed in Section 6, consisted primarily of asking explicitly about employment and non-employment states rather than simply asking about past labor market statuses.

\subsection{Public use microdata access}

Public use microdata from the 2016 wave of the JLMPS, as well as all previous waves of ERF LMPSs, are available through ERF's Open Access Microdata Initiative (OAMDI). Researchers can access the microdata free of charge from the ERF Data Portal ${ }^{5}$ after completing the required registration procedures. The data from individual country surveys can be obtained either as repeated cross section or as panel datasets. Harmonized data across all countries and waves can also be obtained by requesting the Integrated Labor Market Panel Survey (ILMPS) dataset.

\section{Data collection and sample attrition}

\subsection{Data collection and fielding}

Data collection for the 2016 wave proceeded in two phases. First, enumeration was undertaken to track and, if possible, locate the 5,102 households included in the 2010 wave, including any households formed by individuals splitting from 2010 households. Second, fielding was undertaken with located households from 2010 as well as a refresher sample of 3,000 households that over-sampled neighborhoods with a high proportion of non-Jordanian household heads, as ascertained by the 2015 Population Census. The enumeration phase lasted from June 5, 2016 until November 14, 2016 and the main data collection phase lasted from December 10, 2016 until April 27, $2017 .^{6}$

\subsection{0 sample}

The 2010 sample was a nationally representative sample designed to represent urban and rural areas in the three regions of Jordan: North, Middle, and South. For sampling purposes, the sample was stratified into 30 strata based on a combination of the 12 governorates of Jordan and 5 different location classifications within them: (i) basic urban, (ii) rural, (iii) large central city urban in Amman, Zarqa, and Irbid governorates, (iv) suburban Amman and Zarqa, and (v) exurban Amman. The 2010 sample captured 5,102 households and 25,953 individuals. ${ }^{7}$

\subsection{Refresher sample}

A refresher sample was added to the 2016 wave of the JLMPS to capture the large influx of non-Jordanian populations to Jordan. The refresher sample was designed to over-sample

www.erfdataportal.com

6 Additional data collection to capture individuals or households missed in initial fielding continued until September 27, 2017.

7 A few individuals, during 2016 fielding, were determined to have been incorrectly included in the 2010 sample; for example, guests visiting were included but should not have been. These individuals were removed from the revised 2010 data. 
neighborhoods with high concentrations of non-Jordanian household heads as reported by the 2015 Population Census in order to ensure national representativeness in the JLMPS 2016, as well as sufficient observations for analysis of key groups such as Syrian refugees.

\subsubsection{Refresher sample frame}

The sampling frame for the refresher sample was Jordan's 2015 Population and Housing Census. The census was fielded in late November of 2015. Table 2 shows the number of households and individuals in the 2015 Census, by nationality. ${ }^{8}$ In total, there were 1.9 million households and 9.5 million individuals. These census data (geographically disaggregated, as discussed below) are also the source of our expansion factors for the JLMPS weights.

Table 2 Number of households and individuals in 2015 Census, by nationality

\begin{tabular}{lcccccc}
\hline & Jordanian & Syrian & Egyptian & $\begin{array}{c}\text { Other } \\
\text { Arabs }\end{array}$ & $\begin{array}{c}\text { Other } \\
\text { nationalities }\end{array}$ & Total \\
\hline Households & $1,412,157$ & 243,972 & 96,640 & 159,534 & 29,600 & $1,941,903$ \\
Individuals & $6,613,587$ & $1,265,514$ & 636,270 & 818,956 & 197,385 & $9,531,712$ \\
\hline
\end{tabular}

Source: Correspondence with DoS.

Notes: Households are private households (as per Department of Statistics (Jordan), 2015c). Individuals are not restricted to private households as this set of data was not available.

DoS, Jordanian Department of Statistics.

In order to over-sample areas with high proportions of non-Jordanians, we examined the prevalence of households with non-Jordanian heads (hereafter referred to as non-Jordanian households). Our goal was to create two strata: one with a high proportion of nonJordanian households and the other with a low proportion of non-Jordanian households, in order to oversample the former. The prevalence of non-Jordanian households was assessed at the lowest administrative level possible, namely, the neighborhood (hayy). This is the cluster or primary sampling unit (PSU) level that we used for drawing our refresher sample. Our "high" non-Jordanian stratum consisted of neighborhoods in the top decile of the prevalence of non-Jordanian households. These were neighborhoods with $45.7 \%$ non-Jordanian households and higher. All other neighborhoods in Jordan constitute our "low" non-Jordanian stratum. We further stratified our refresher sample along two dimensions: governorate and location (urban, rural, or refugee camps). The camps were two of the three official refugee camps in Jordan: Za'atari refugee camp, in the Mafraq governorate, and Azraq refugee camp, in the Zarqa governorate. The third, the EmiratiJordanian camp in Zarqa governorate, is much smaller than the other two and was not included in the sample.

\subsubsection{Planned sample design}

The high non-Jordanian and camps strata were both over-sampled in order to provide a sufficient number of observations for research and analysis. This over-sampling strategy is accounted for in our weights, discussed below. Across the strata, a total of 200 PSUs (neighborhoods) were

8 Based on spreadsheets provided by the Department of Statistics. 


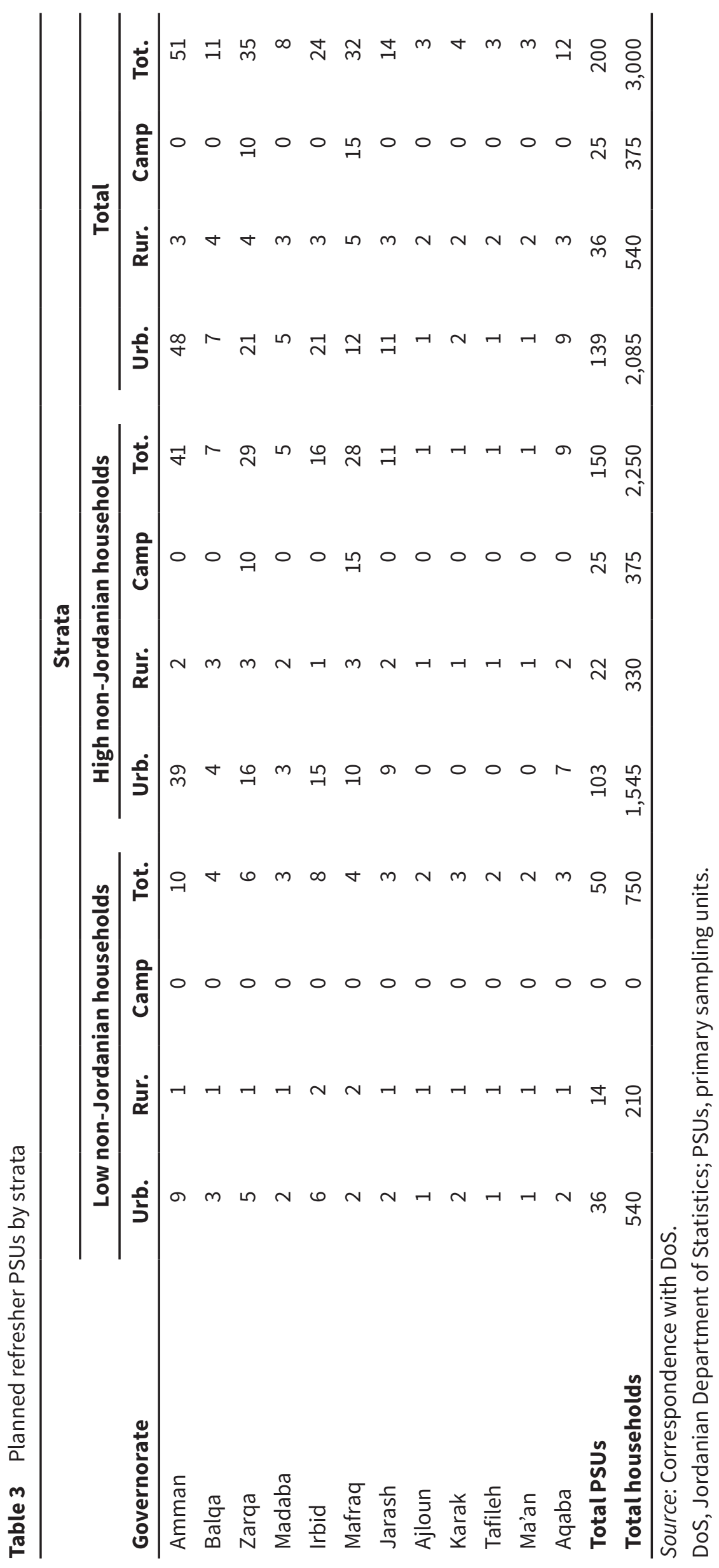


selected, of which 150 fell in the "high" non-Jordanian and 50 in the "low" non-Jordanian. The distribution of PSUs by governorate and urban/rural/camps is shown in Table 3. Within each PSU, the plan was to sample 15 households. ${ }^{9}$

\subsubsection{Deviations from the planned sample in fielding implementation}

There were a few deviations from planned sampling during implementation. First, in the "high" strata an additional PSU in urban Amman and an additional PSU in rural Amman were added. Ajloun and Tafileh "high" strata rural areas were not sampled. One less PSU was drawn from the "high" stratum rural area in Mafraq. ${ }^{10}$ In total, 199 PSUs were sampled. There were also some deviations from the planned number of households in each PSU. The goal was to sample 15 households per PSU, and for 93.5\% of PSUs, this was achieved. Most other PSUs (3.5\%) sampled 14 households. Two PSUs sampled only 13 households, one PSU only 12 households, two PSUs only 11 households, and one PSU only 2 households. Overall, the mean response rate was $98.8 \%$. Within the different dimensions of the strata, missing households were slightly more common in rural areas: a 97.8\% response rate in rural areas, a $98.9 \%$ response rate in urban areas, and a $100 \%$ response rate in the camps. These response rates on the PSU level are factored into our sample weights, as discussed below. Ultimately, of a planned 3,000 households, our refresher sample contained 2,950 households with 13,423 individuals.

\subsection{Panel sample attrition}

For the panel data, tracking households from 2010 to 2016, a key issue is sample attrition. There are two points in time when attrition can occur: between the 2010 wave and 2016 enumeration and between the 2016 enumeration and 2016 fielding. There are also two types of attrition that can occur: Type I attrition occurs when we cannot locate a 2010 household at all, while Type II attrition occurs when we can locate a 2010 household, it has a split, and we cannot locate the split household. ${ }^{11}$ Attrition, if it is nonrandom, will create bias in the sample. Assessing and weighting to account for observable attrition, to the extent possible, is important to reduce bias. This section discusses the patterns of the two different types of attrition and the next section presents the models predicting attrition that are used as inputs for generating the sample weights.

\subsubsection{Attrition of entire households (Type I attrition)}

In undertaking the enumeration and fieldwork, a key goal was to locate as many of the 2010 households as possible. From the original 2010 sample of 5,102 households, 3,427 were successfully found at the enumeration stage (Table 4). In the cases when households were not located, data were collected, where possible, on the status of the household or the reason they were not present. During enumeration, there were 81 households that had left the country entirely (all

9 Two extra households were drawn from each cluster as back-ups if a planned household was not found.

10 The reason for these deviations was that the identified high-non-Jordanian rural areas could not be found.

11 Since attrition could occur at two points in time, there were some cases in which the original household and a split were both found during enumeration, but only the split was found in fielding. In these cases, we reclassified the split to be the original household and the original household, not found in fielding, to be the split so that attrition could be modeled and the households reclassified from splits to original included in the data. 
Table 4 Status of households at enumeration and fielding

\begin{tabular}{lccc}
\hline & Enumeration & $\begin{array}{c}\text { Updates between } \\
\text { enumeration and fielding }\end{array}$ & Final status \\
\hline Initial households & 5,102 & 3,427 & 5,102 \\
Located & 3,427 & 3,058 & 3,058 \\
Could not be found & 1,481 & 178 & 1,659 \\
Refused & 69 & 157 & 226 \\
All left the country & 81 & 26 & 107 \\
All died & 44 & 8 & 52 \\
Type I attrition rate & 31.1 & 9.9 & 38.1 \\
\hline
\end{tabular}

Source: Authors' calculations based on JLMPS 2010 and JLMPS 2016.

JLMPS, Jordan Labor Market Panel Survey.

members departed) and 44 households that had all their members die. We refer to these cases of all the members leaving or dying as "natural attrition." We do not include cases of natural attrition in our calculation of attrition rates or in our attrition models, since they are no longer part of the relevant universe for our survey.

At the enumeration stage, we were unable to locate 1,481 households and 69 households refused (both these results are forms of attrition). Thus, our Type I attrition rate was 31.1\% at the enumeration stage. After updates during fielding, from the 3,427 households found during enumeration, 26 households left the country, 8 had died, 178 could not be found, and 157 refused. Of the 5,102 households from 2010, 3,058 remained in the sample. Thus, accounting for natural attrition, our final Type I attrition rate was 38.1\%. This compares to a Type I attrition rate of 23.5\% in the ELMPS from 1998 to 2006 and 17.3\% from 2006 to 2012. ${ }^{12}$ This relatively high attrition rate is presumably due to the larger proportion of more mobile non-citizens living in Jordan compared with Egypt, and the relatively higher residential mobility of the population in the Jordanian setting.

\subsubsection{Attrition of split households (Type II attrition)}

Tracking splits is important for maintaining sample representativeness. While the older generation may be located in the original household, young people may split off to form new households (Himelein, 2014). If these new households are not tracked, the sample ages (relative to the population). Likewise, splits and moves may be related to increases in income (Thomas et al., 2012) or life events such as education, employment, or marriage that are critically important to maintaining representativeness. For example, in the Living Standards Measurement Surveys - Integrated Surveys on Agriculture (LSMS-ISA) project, youth, urban residents, and men were disproportionately likely to split and attrite (Himelein, 2014). Modeling and accounting for this attrition are critical. Carefully tracking splits is particularly important for capturing groups such as internal migrants (Beegle et al., 2011).

One of the lessons we learned from ELMPS 2012 was that we need to account for attrition between enumeration and fielding on the individual level as well as the household level. We therefore included essentially the same questions as from enumeration in order to update the

12 See Assaad and Roushdy (2009) for an analysis of attrition in the 2006 wave of the ELMPS and Assaad and Krafft (2013) for the 2012 wave. 
disposition of different individuals who were in the 2010 wave and present at enumeration. This also allowed us to track additional split households that occurred between enumeration and fielding. Unfortunately, the additional split households were not followed up in the field. However, we can use the data on individuals who died, left the country, or moved to group housing, thus leaving the survey universe, between enumeration and fielding to assess natural attrition as distinct from Type II attrition. Split households between enumeration and fielding thus contribute to Type II attrition.

Table 5 shows the status of individuals at enumeration and fielding. The status of individuals is only shown for those whose 2010 household was found. The households found in enumeration originally contained 18,227 individuals in 2010. Of these, 15,617 were still present in their original households at the enumeration stage. Among those no longer present, 4 had moved to group housing, 234 emigrated, and 382 died, totaling 620 individuals who left the sample due to natural attrition. The remaining 1,990 individuals formed split households. Since individuals can split together, we identify individuals who form a new household together as one "split household." There were 1,911 split households at enumeration, of which 1,536 were found, for a Type II attrition rate of $19.6 \%$.

Since additional households were lost between enumeration and fielding, there were only 15,357 individuals from 2010 who could potentially be in their original (or split) household at the fielding stage. We successfully located 14,502 of these individuals from 2010 during fielding. Of the 855 individuals lost, 208 were lost to natural attrition, and 647 were lost into 616 split households. When looking at the final status of individuals, there were 16,631 individuals

Table 5 Status of individuals at enumeration and fielding

\begin{tabular}{|c|c|c|c|}
\hline & Enumeration & $\begin{array}{c}\text { Updates between } \\
\text { enumeration } \\
\text { and fielding }\end{array}$ & $\begin{array}{l}\text { Final } \\
\text { status }\end{array}$ \\
\hline $\begin{array}{l}\text { Individuals present in } 2010 \text { in a household } \\
\text { found in } 2016 / 17\end{array}$ & 18,227 & 15,357 & 16,631 \\
\hline $\begin{array}{l}\text { Individuals still in original households in } \\
2016 / 17\end{array}$ & 15,617 & 14,502 & 13,235 \\
\hline $\begin{array}{l}\text { Individuals no longer in original } \\
\text { households in 2016/17 }\end{array}$ & 2,610 & 855 & 3,396 \\
\hline $\begin{array}{l}\text { Natural attrition through death, migration, } \\
\text { or group housing }\end{array}$ & 620 & 208 & 757 \\
\hline Individuals known to have died & 382 & 59 & 406 \\
\hline Individuals known to have emigrated & 234 & 64 & 264 \\
\hline $\begin{array}{l}\text { Individuals known to have moved to group } \\
\text { housing }\end{array}$ & 4 & 85 & 87 \\
\hline Individuals split to form households & 1,990 & 647 & 2,639 \\
\hline $\begin{array}{l}\text { Potential split households (accounting for } \\
\text { individuals who split together) }\end{array}$ & 1,911 & 616 & 2,465 \\
\hline Split households found & 1,536 & 0 & 1,221 \\
\hline Split households not found (attrited) & 375 & 616 & 1,244 \\
\hline Type II attrition rate & 19.6 & 100.0 & 50.5 \\
\hline
\end{tabular}

Source: Authors' calculations based on JLMPS 2010 and JLMPS 2016. JLMPS, Jordan Labor Market Panel Survey. 
who were present in 2010 in the households that were successfully found at fielding. Of these, 13,235 individuals were found in their original households. Of the remaining 3,396, in total 757 were lost to natural attrition. There were 2,639 individuals who split into 2,465 split households. Multiple split households may have split from a 2010 household. For example, a family with two teenaged daughters in 2010 may have had both daughters marry and leave home to form two separate split households. The proportion of households that were located in fielding in 2016 who experienced a split was $41 \%$ (1,257 households had one or more splits from the 3,058 found from 2010). Of the 2,465 split households, 1,221 were found, implying a Type II attrition rate of $50.5 \%$.

Again, this is relatively high, when compared with the Type II attrition rates in the ELMPS, which were $15.4 \%$ from 1998 to 2006 and 30.3\% from 2006 to 2012, and when compared with the Type II attrition rate from the enumeration stage. This high rate is due to the additional 616 split households identified during the fielding stage, none of which were successfully located, and another 315 split households found during enumeration and not successfully located during fielding. This was due to some problems that arose during the fielding stage related to tracking these individuals. ${ }^{13}$ In what follows, we develop models to predict both Type I and Type II attrition in order to construct the appropriate attrition weights.

\section{Sample weights}

\subsection{Models of sample attrition}

We model sample attrition for two reasons. First, we wish to examine whether attrition is random or related to household characteristics. Second, if there are differences in attrition related to observable characteristics, we account for these differences by creating appropriate weights. While we cannot correct for attrition related to unobserved household characteristics, we try to reduce their influence by including as many observable characteristics as possible as predictors in the model. Table 6 presents odds ratio estimates from a logit model, on the household level, for Type I attrition. Households that naturally attrited are excluded from the model, resulting in a universe of 4,943 households from 2010 at risk of Type I attrition. Characteristics are, necessarily, those measured in $2010 .^{14}$

There are some significant predictors of Type I attrition. In terms of household composition, households with more working age and especially more elderly (65+) females were significantly less likely to attrite. Households composed of all males, compared to mixed sex households, were significantly more likely to attrite. There were no significant differences by the geographic strata that were used in 2010 for stratifying the sample, which is encouraging for sample representativeness. Households in the top wealth decile were significantly more

13 Given the repeated problems with losing individuals from enumeration to fielding in ELMPS 2012 and JLMPS 2016, we no longer implemented a separate enumeration round starting in ELMPS 2018, but rather fielded immediately upon finding a household and collected data on any splits to subsequently track (Krafft et al., 2019).

14 We use a logit model rather than a probit model because it produces odds ratios that are more readily interpretable than probit coefficients. The logit model is commonly used to model attrition (e.g., Himelein, 2014). We do not include nationality of household head in attrition models because it would assume no migration occurs. Furthermore, we calculate our weights by nationality to reflect the population distribution by nationality observed in the 2015 Population Census. 
Table 6 Type I attrition logit model: Probability household attrited.

Household composition (no. of)

No. of children 0-5 in household

1.002

(0.042)

No. of children 6-14 in household

0.977

(0.029)

No. of WA males in household

0.938

(0.036)

No. of WA females in household

$0.891^{\star \star}$

No. of elderly males in household

0.713

(0.144)

No. of elderly females in household

$0.548^{\star \star \star}$

$(0.084)$

Single sex households (mixed sex omitted)

All male

$2.022^{\star}$

All female

1.112

(0.233)

Strata (urban not large city omitted)

Rural

Central large city

1.200

(0.128)

Suburban large city

0.854

(0.111)

Exurbs

1.510

$(0.333)$

Wealth decile (poorest omitted)

Deciles of household wealth $=2$

Deciles of household wealth $=3$

0.765

(0.142)

Deciles of household wealth $=4$

(0.184)

Deciles of household wealth $=5$

0.891

(0.166)

Deciles of household wealth $=6$

0.931

Deciles of household wealth $=7$

0.990

(0.187)

Deciles of household wealth $=8$

1.001

(0.191) 
Table 6 Continued

Deciles of household wealth $=9$

1.275

$(0.252)$

Deciles of household wealth $=10$

$2.332^{\star \star \star}$

(0.492)

Wealth decile and location ints.

Deciles of household wealth $=2$ \# rural

1.158

$(0.355)$

Deciles of household wealth = 3 \# rural

1.254

Deciles of household wealth $=4 \#$ rural

0.617

(0.204)

Deciles of household wealth $=5$ \# rural

1.007

(0.329)

Deciles of household wealth $=6 \#$ rural

0.884

$(0.308)$

Deciles of household wealth $=7$ \# rural

0.846

$(0.297)$

Deciles of household wealth $=8 \#$ rural

Deciles of household wealth = $9 \#$ rural

Deciles of household wealth $=10 \#$ rural

0.417

(0.247)

Governorate (Amman omitted)

Balqa

0.904

$(0.157)$

Zarqa

1.029

(0.117)

Madaba

0.679

(0.153)

Irbid

1.038

(0.121)

Mafraq

1.379

(0.285)

Jarash

0.715

$(0.147)$

Ajloun

0.898

(0.215)

Karak

$0.378^{\star \star \star}$

(0.094)

Tafileh

$0.225^{\star \star \star}$

(0.072) 
Table 6 Continued

\begin{tabular}{|c|c|}
\hline \multirow[t]{2}{*}{ Ma'an } & $0.513^{\star}$ \\
\hline & $(0.140)$ \\
\hline \multirow[t]{2}{*}{ Aqaba } & $2.531^{\star \star \star}$ \\
\hline & $(0.656)$ \\
\hline \multicolumn{2}{|c|}{ Governorate and location ints. } \\
\hline \multirow[t]{2}{*}{ Balqa \# rural } & 0.576 \\
\hline & $(0.185)$ \\
\hline \multirow[t]{2}{*}{ Zarqa \# rural } & $0.375^{\star}$ \\
\hline & $(0.153)$ \\
\hline \multirow[t]{2}{*}{ Madaba \# rural } & 1.403 \\
\hline & $(0.564)$ \\
\hline \multirow[t]{2}{*}{ Irbid \# rural } & $0.465^{\star \star}$ \\
\hline & $(0.137)$ \\
\hline \multirow[t]{2}{*}{ Mafraq \# rural } & 0.653 \\
\hline & $(0.207)$ \\
\hline \multirow[t]{2}{*}{ Jarash \# rural } & 0.695 \\
\hline & $(0.250)$ \\
\hline \multirow[t]{2}{*}{ Ajloun \# rural } & 0.575 \\
\hline & $(0.268)$ \\
\hline \multirow[t]{2}{*}{ Karak \# rural } & 1.060 \\
\hline & $(0.387)$ \\
\hline \multirow[t]{2}{*}{ Tafileh \# rural } & $3.221^{\star}$ \\
\hline & $(1.559)$ \\
\hline \multirow[t]{2}{*}{ Ma'an \# rural } & 1.055 \\
\hline & $(0.472)$ \\
\hline \multirow[t]{2}{*}{ Aqaba \# rural } & $0.071^{\star \star \star}$ \\
\hline & $(0.049)$ \\
\hline \multicolumn{2}{|c|}{ Homeownership (not owned omitted) } \\
\hline \multirow[t]{2}{*}{ Owned } & $0.252^{\star \star \star}$ \\
\hline & $(0.019)$ \\
\hline \multicolumn{2}{|c|}{ Head age group (less than 25 omitted) } \\
\hline \multirow[t]{2}{*}{$25-34$} & 0.772 \\
\hline & $(0.209)$ \\
\hline \multirow[t]{2}{*}{$35-44$} & 0.829 \\
\hline & $(0.229)$ \\
\hline \multirow[t]{2}{*}{$45+$} & 0.729 \\
\hline & $(0.208)$ \\
\hline \multicolumn{2}{|c|}{ Head sex (male omitted) } \\
\hline \multirow[t]{2}{*}{ Female } & 0.412 \\
\hline & $(0.308)$ \\
\hline \multicolumn{2}{|c|}{ Head age and sex ints. } \\
\hline \multirow[t]{2}{*}{ 25-34 \# female } & $3.763^{\star}$ \\
\hline & $(2.509)$ \\
\hline
\end{tabular}


Table 6 Continued

35-44 \# female

$(0.560)$

45+ \# female

Head marital status (single omitted)

Married

Divorced

Widowed

Head marital status and sex ints.

Married \# female

Divorced \# female

Widowed \# female

1.581

$(0.967)$

Head ed. (less than basic omitted)

Basic

Secondary

$1.253^{\star}$

$(0.137)$

Higher education

$1.366^{\star \star}$

$(0.149)$

Head labor market status (Public sector omitted)

Formal private wage

Informal private wage

1.180

$(0.166)$

Nonwage

1.202

(0.152)

OLF

0.867

(0.122)

Unemployed

$0.563^{*}$

(0.131)

Out of manpower

$1.626^{*}$

$(0.380)$

Head labor market status and location ints.

Formal private wage \# rural 
Table 6 Continued

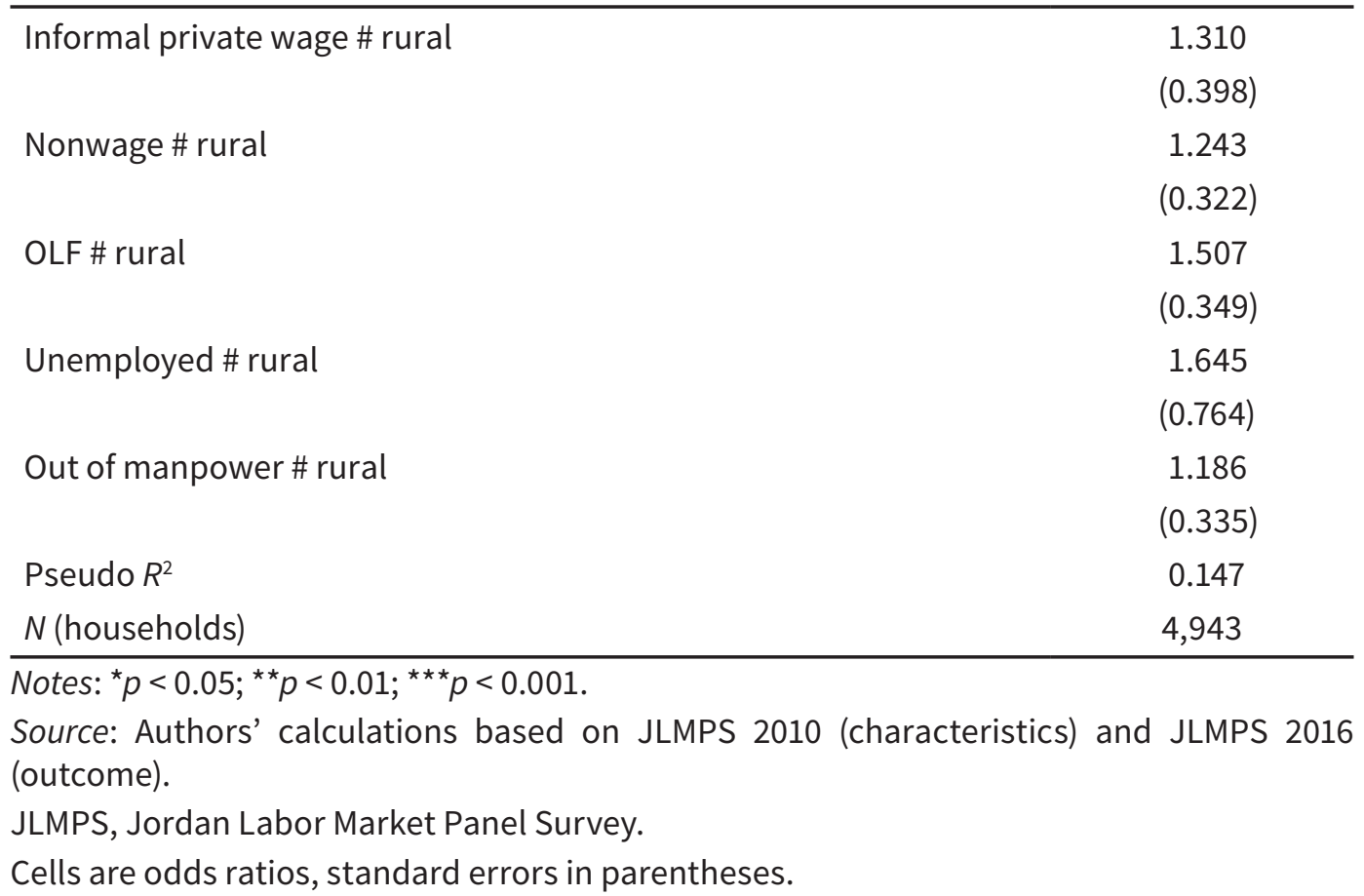

likely to attrite than the poorest, but there were no significant odds ratios for other deciles. The higher attrition in the top decile was driven by urban areas. ${ }^{15}$

In terms of governorates, there are significantly lower odds of Type I attrition for (the reference, urban) Karak, Tafileh, and Ma'an, but higher odds of attrition in urban Aqaba (all in the South region), compared with Amman. Karak and Ma'an's interactions with rural are near one and insignificant, so the lower odds of Type I attrition pertain to rural areas of these regions as well. There are significant interactions with rural, lower odds of attrition, for Zarqa, Irbid, and Aqaba, compared with their urban counterparts, and significantly higher odds in rural Tafileh, compared with urban Tafileh. Homeownership as opposed to renting predicts significantly lower attrition. There were no significant differences by head age group, or sex, although households headed by females aged 25-34 years were significantly more likely to attrite. There were no significant differences by marital status, but there was a significantly higher probability of attrition for households with divorced female heads.

Households with more educated heads were more likely to attrite, significantly so for secondary and higher education, as compared to less than basic. There were few significant labor market characteristics of the household head, which bodes well for the labor market representativeness of our panel. Households with unemployed household heads were significantly less likely to attrite, while those out of the manpower basis (disabled or elderly) were more likely to attrite than the reference household head, who was employed in the public sector. There were no significant labor market status interactions with the rural dummy. Overall, the model had a pseudo- $R^{2}$ of $14.7 \%$. In this case, a low pseudo- $R^{2}$

15 Although the tenth decile rural interaction is insignificant, it shows lower odds of attrition, cancelling the higher odds of tenth decile main effect. The higher Type I attrition in the top decile of urban areas is presumably due to a higher rate of refusals among this category of respondents, which are generally known to be less cooperative in face-to-face household surveys (Hlasny and Verme, 2018). 
is a good outcome, as it means that only a limited portion of the probability of attrition can be explained by this long list of observable characteristics and that much of the rest is presumably random.

For the Type II attrition model (Table 7), the sample is restricted to those 2,386 splits with heads aged $6+$ years (who have individual characteristics from 2010). ${ }^{16}$ Since most split households are made up of just one member who split off from his or her original household alone, we only model composition in terms of additional working age males and females. In fact, there are significantly lower odds of Type II attrition for split households with additional working age males, meaning that when two or more individuals split together they are easier to trace. There are significantly higher odds of Type II attrition for strata other than the reference urban (not large city). Splits from rural areas and the exurbs of Amman in particular have significantly higher odds of attrition. There are significantly higher odds of attrition for a number of wealth quintiles compared to the poorest, although the differences essentially imply that splits from the poorest quintile are less likely to attrite. There are some significantly lower odds of attrition for wealth rural interactions. As was the case for Type I attrition, it appears to be primarily urban and wealthier households that are driving the differences in attrition. Greater mobility or higher opportunity cost of time for these households may be behind these dynamics. Only splits from Madaba have significantly different (higher) odds of attrition than those of other governorates. There are no significant rural and governorate interactions. Splits from households that owned their home are significantly less likely to attrite. Compared with split household heads younger than 25, only those aged $45+$ years are significantly more likely to attrite. The odds ratio here is high; one possible reason is that these are splits where the split was due to natural attrition, but that this was not captured in the field.

Female-headed splits are significantly less likely to attrite, although the female and 25-34 years age group interaction indicates significantly higher odds of attrition for females in that age group. Compared to those splits with less than basic educated heads, other categories are less likely to attrite, all but higher education significantly so. This may be related to the ability of the remaining household members to accurately communicate the new location. Compared to splits with household heads who were public sector workers in 2010, splits with formal private wage, informal wage, and out of labor force heads are more likely to attrite. Overall, the pseudo- $R^{2}$ of the Type II attrition model is $10.0 \%$, again indicating that most of the Type II attrition is not systematically related to observable characteristics.

\subsection{Calculation of sample weights: Panel sample}

Weights are initially constructed at the household level. Two essential inputs are the results of the Type I and Type II attrition models. For an original (2010) household, denote the household as $h \cdot{ }^{17}$ Denote a household that split (whether found or not) as $s$. We use our

16 Essentially, we are assuming that split households with heads less than age 6 years are unlikely to be "real" split households, but rather that we are simply missing information about these individuals (for instance, that they died). For those few splits with "heads" aged 0-5 years, we use the mean predicted probability of attrition while weighting.

17 The start of this section draws on the concepts and notation used for the ELMPS 2012 (Assaad and Krafft, 2013). 
Table 7 Type II attrition logit model: Probability split household attrited.

Split household composition (no. of)

No. of WA males in household

$0.529^{\star}$

(0.147)

No. of WA females in household

Strata (urban not large city omit.)

Rural

$2.918^{\star \star}$

(1.164)

Central large city

$1.683^{\star \star}$

(0.310)

Suburban large city

(0.235)

Exurbs

$3.361^{*}$

Wealth decile (poorest omitted)

Deciles of household wealth $=2$

Deciles of household wealth $=3$

$2.169^{\star \star}$

(0.588)

Deciles of household wealth $=4$

$1.807^{\star}$

Deciles of household wealth $=5$

1.546

Deciles of household wealth $=6$

$2.118^{\star \star}$

Deciles of household wealth $=7$

1.647

(0.459)

Deciles of household wealth $=8$

$2.157^{\star \star}$

(0.606)

Deciles of household wealth $=9$

$2.159^{\star \star}$

(0.605)

Deciles of household wealth $=10$

$2.551^{\star \star}$

Wealth decile and location ints.

Deciles of household wealth $=2$ \# rural

$(0.252)$

Deciles of household wealth $=3$ \# rural

$0.377^{\star}$

Deciles of household wealth $=4$ \# rural

$0.418^{\star}$

(0.171)

Deciles of household wealth $=5$ \# rural

0.734

$(0.297)$ 
Table 7 Continued

Deciles of household wealth $=6$ \# rural

$(0.224)$

Deciles of household wealth $=7$ \# rural

0.501

(0.213)

Deciles of household wealth $=8$ \# rural

$0.417^{\star}$

(0.185)

Deciles of household wealth $=9 \#$ rural

$0.324^{\star}$

Deciles of household wealth $=10 \#$ rural

Governorate (Amman omitted)

Balqa

Zarqa

1.010

(0.192)

Madaba

$3.045^{\star \star}$

(1.130)

Irbid

1.213

$(0.234)$

Mafraq

1.261

$(0.374)$

Jarash

1.223

(0.328)

Ajloun

0.947

(0.286)

Karak

0.667

(0.213)

Tafileh

0.738

$(0.256)$

Ma'an

0.834

$(0.272)$

Aqaba

1.935

(0.951)

Governorate and location ints.

Balqa \# rural

(0.220)

Zarqa \# rural

1.052

(0.462)

Madaba \# rural

0.862

(0.488)

Irbid \# rural

0.798

$(0.294)$ 
Table 7 Continued

Mafraq \# rural

0.637

$(0.261)$

Jarash \# rural

1.168

$(0.468)$

Ajloun \# rural

0.574

$(0.292)$

Karak \# rural

0.881

(0.382)

Tafileh \# rural

(0.395)

Ma'an \# rural

$(0.277)$

Aqaba \# rural

0.417

$(0.275)$

Homeownership (not owned omit.)

Owned

$0.683^{\star}$

$(0.114)$

Head age group (less than 25 omitted)

25-34

0.958

(0.146)

$35-44$

1.595

(0.746)

$45+$

$9.472^{\star \star \star}$

(4.944)

Head sex (male omitted)

Female

$0.484^{\star}$

(0.148)

Head age and sex ints.

25-34 \# female

$2.767^{\star \star \star}$

(0.636)

35-44 \# female

1.830

(1.077)

45+ \# female

0.789

$(0.536)$

Head ed. (less than basic omitted)

Basic

$0.698^{\star \star}$

(0.094)

Secondary

$0.593^{\star \star \star}$

(0.086)

0.825

(0.150)

Higher education 
Table 7 Continued

\section{Head labor market status (Public sector omitted)}

Formal private wage

Informal private wage

Nonwage

OLF

Unemployed

Out of manpower

Pseudo $R^{2}$

$N$ (split households)

Notes: ${ }^{\star} p<0.05 ;{ }^{\star \star} p<0.01 ;{ }^{\star \star \star} p<0.001$.

Source: Authors' calculations based on JLMPS 2010 (characteristics) and JLMPS 2016 (outcome).

JLMPS, Jordan Labor Market Panel Survey.

Cells are odds ratios, standard errors in parentheses.

Type I attrition model to calculate the probability of attrition of the entire household, which we denote as $\operatorname{Pr}\left(A_{h}\right)$. Furthermore, for split households, we calculate the probability of attrition as $\operatorname{Pr}\left(A_{h s}\right)$ :

$$
\begin{aligned}
\operatorname{Pr}\left(A_{h s}\right) & =\operatorname{Pr}(h \text { found \& s not found })+\operatorname{Pr}(h \text { not found }) \\
& =\operatorname{Pr}(s \text { not found } \mid h \text { found }) \star[1-\operatorname{Pr}(h \text { not found })]+\operatorname{Pr}(h \text { not found })
\end{aligned}
$$

Or, alternatively and equivalently:

$$
\begin{aligned}
\operatorname{Pr}\left(A_{h s}\right) & =1-\operatorname{Pr}(h \text { found } \& s \text { found }) \\
& =1-\operatorname{Pr}(h \text { found }) \star \operatorname{Pr}(s \text { found } \mid h \text { found })
\end{aligned}
$$

We then can compute a response adjustment factor, $r_{h}$ for original households as:

$$
r_{h}=\frac{1}{1-\operatorname{Pr}\left(A_{h}\right)}
$$

For the split sample the response adjustment factor is:

$$
r_{h s}=\frac{1}{\left[1-\operatorname{Pr}\left(A_{h s}\right)\right]^{\star} c_{s}}
$$

Here the adjustment includes $c_{s}$, the number of component households. Essentially, component households are the number of different originating households in the population (not the sample) that contribute to a split household. If the split contains only individuals from a 2010 household, there is only one component household. If the split contains individuals 
not from a 2010 household, there are two component households. Accounting for component households in this manner maintains population representativeness. ${ }^{18}$

The calculation of our panel sample weights also brings in the weights from 2010. Denote as $e$ the expansion weight from 2010. ${ }^{19}$ We generate our panel weights, $w$, initially as $w=e^{\star} r_{h(s)}$. We then normalize the weights (dividing by the mean to have a mean of one), which enables subsequent combination with the refresher sample on a one-to-one basis. Before we discuss the combined, full sample weights, we discuss the refresher weights.

\subsection{Calculation of sample weights: Refresher sample}

The refresher sample weights both stand alone, should someone want to analyze the refresher sample only (for instance, as an additional validation check), and act as inputs into the combined sample weights. As with the panel sample, weights are calculated on a household level. We first account for nonresponse at the PSU level, $p$, with a weight, $w_{p}$, based on the number of observed households, $m_{p}$ as:

$$
w_{p}=\frac{15}{m_{p}}
$$

Essentially, the observed households in clusters with nonresponse are weighted up to represent the planned 15 households. Otherwise, this weight is one.

Recall that the refresher sample was stratified along governorate, urban/rural/camps and high/low non-Jordanian lines. Denote governorate as $g$, urban/rural/camps (location) as $l$, and high/low non-Jordanian strata as $s$. We undertake ex-post weighting along nationality, $n$, lines. We therefore identify the response-corrected number of households, $h_{g, l, s, n}$, of each nationality $n$ in each governorate $g$ in location $l$ and high-low stratum $s$ by summing across PSUs as in:

$$
h_{g, l, s, n}=\sum_{p=1}^{p} w_{p}{ }^{\star} h_{p, g, l, s, n}
$$

We then draw on the census data for the nationality-specific number of households in the same governorate, location, and strata, $c_{g, l, s, n}$. After accounting for PSU-level nonresponse, this implies an expansion weight of:

$$
w_{p, g, l, s, n}=w_{p} \frac{c_{g, l, s, n}}{h_{g, l, s, n}}
$$

Although at this point the weight is conceptually correct, two empirical problems arise. First, there are some extreme outliers within the weight distribution, which are particularly problematic when analyzing subgroups. These are primarily driven by instances in which we observed only a few households of a particular non-Jordanian nationality in a combination of governorate, location, and strata. We therefore winsorized the high end of our weight, at the 95th percentile. We denote the winsorized weight as $w_{p, g, l, s, n}^{\prime}$.

18 For panel analyses using only observations present in both 2010 and 2016, the specific panel weight does not include the division by component households.

19 There was some individual variation in weights within households in 2010 for some households, which was averaged out in the revised data for JLMPS 2010 and to enable generation of weights for 2016. 
The other empirical problem is that we do not always have, in our sample, individuals from all nationalities in each combination of governorate, location, and strata. For Jordanians, we are very close to the national population. However, we under-represent other nationalities to an increasing extent as their numbers diminish. Additionally, the winsorizing reduces numbers somewhat. Therefore, to ensure that our statistics represent nationalities appropriately within the country, we revise the weights, multiplying up to represent higher levels of aggregation. Specifically, we use from the 2015 Population Census the number of households of a nationality within a region, $r$ (there are three regions), and area, specifically inside or outside of camps, which we denote as $a$. We use the census number of households relative to the weighted, winsorized, observed households as a multiplier on our weights, aggregating over governorates (from 1 to $\mathrm{G}$ ) within a region, locations (from 1 to $\mathrm{L}$ within a governorate and area), and strata, to generate an adjusted weight:

$$
w_{p, g, r, l, a, s, n}=w_{p, g, l, s, n}^{\prime} * \frac{c_{r, a, n}}{\sum_{g=1}^{G} \sum_{l=1}^{L_{g, a}} \sum_{s=1}^{2} w_{p, g, l, s, n}^{\prime}}
$$

Here the denominator includes only those governorates within the region and only the locations within the area.

This approach generates mathematically identical numbers of households at the national level. On the individual level, it does very well for representing Jordanians (expanding to around 6,603,000, very close to the census) and Syrians (expanding to around 1,268,000, also very close to the census). Other groups have fewer individuals, likely due to the fact that many of these individuals are immigrants who may live in collective housing, rather than private households. We expand to around 546,000 other Arabs (underestimated by around 272,000), 185,000 Egyptians (underestimated by around 451,000), and around 58,000 other nationalities (underestimated by around 139,000). Ultimately, our sample expands to 8,661,000 individuals, whereas there were 9,293,000 individuals in private households according to the 2015 Census. Given the sizes of households we observe and those implied in the census data, it is likely that the sampling frame was more stringent in identifying private households, and thus underrepresents those other nationalities living collectively.

An additional problem on the individual level arises in that, in addition to household-level consent, we collected individual-level consent and had some refusals (69 in the refresher sample and 172 in the panel sample) as well as some individual questionnaires that were only partially completed (12 in the refresher sample and 58 in the panel sample). We removed the partial individual data and treated both cases as individual nonresponse. The only characteristics we have for these individuals are the basic characteristics from the roster. Upon examination, we determined that there were sex- and age-specific patterns of individual nonresponse. To address both the under-representation of certain types of individuals and individual nonresponse, we created individual-level weights. The starting point for these individual-level weights was the household-level weight. We adjusted this household-level weight by the age, $e$, and sex-specific, $x$, interacted nonresponse rate, $r_{e, x}$ as:

$$
w_{p, g, r, l, a, s, n, x, e}=\frac{w_{p, g, r, l, a, s, n}}{1-r_{e, x}}
$$


We then summed the household-weighted number of individuals with valid responses and multiplied it by the ratio of that number to the number in the population on the region, areas, and nationality levels from the 2015 Census, which we denote as $j_{a, r, n}$ Essentially, we calculated an individual expansion weight, $i$, of:

$$
i_{p, g, r, l, a, s, n, x, e}=w_{p, g, r, l, a, s, n, x, e} * \frac{j_{r, a, n}}{\sum_{r, a} w_{p, g, r, l, a, s, n, x, e}}
$$

These individual weights (mathematically) generate expanded numbers of individuals that are identical to the census on the region, area, and nationality levels.

\subsection{Calculation of sample weights: Combined sample cross-sectional weights}

The calculation of weights for the combined sample starts with the normalized panel and refresher sample weights (meaning weights that average to one in each sample). As with the refresher sample weights, we do ex-post weighting on a nationality, governorate, and location basis. Since the initial sample was not stratified by high/low non-Jordanian that dimension is not incorporated explicitly into the combined sample weights, but is built in implicitly through the refresher sample weights. Denote the normalized weights for a household in governorate $g$, location $l$, and nationality $n$ as $\tilde{w}_{g, l, n}$. We calculated the initial combined sample weights as:

$$
w_{g, l, n}=\tilde{w}_{g, l, n} * \frac{c_{g, l, n}}{\sum \tilde{w}_{g, l, n}}
$$

where $c_{g, l, n}$ are the number of households from the 2015 Census at the governorate, location, and nationality levels. As with the refresher weights, we winsorize at the 95th percentile to address outliers. We denote the winsorized weight as $w_{g, l, n}^{\prime}$. We then need to account for the absence of some nationalities in combinations of governorate and location. Again, we use the number of households of a nationality within a region, $r$, and area (inside or outside of camps), $a$ from the 2015 Census. We use the census number of households relative to the weighted, winsorized, observed households as a multiplier on our weights, aggregating over governorates (from 1 to $\mathrm{G}$ ) within a region and location (from 1 to $\mathrm{L}$ ) within governorates, to generate an adjusted weight:

$$
w_{g, r, l, a, n}=\frac{c_{r, a, n}}{\sum_{g=1}^{G} \sum_{l=1}^{L_{g, a}} w_{g, l, n}^{\prime}}
$$

As was the case with the refresher weights, we find that this under-represents individuals, particularly non-Jordanians, and also we again have an issue of non-response on the individual level, so for the combined sample we also generate individual weights that account for age and sex-specific individual non-response, $r_{e, x}$, as:

$$
w_{g, r, l, a, n, x, e}=\frac{w_{g, r, l, a, n}}{1-r_{e, x}}
$$


We then adjust this by the census number of individuals in a specific area and region of the same nationality to generate an individual weight, $i$ :

$$
i_{g, r, l, a, n, x, e}=w_{g, r, l, a, n, x, e} * \frac{j_{r, a, n}}{\sum_{r, a} w_{g, r, l, a, n, x, e}}
$$

The individual weights should be used when trying to generate individual-level statistics, particularly those incorporating any data from the individual questionnaire.

\section{Comparison of JLMPS data to other Jordanian data}

In order to assess the representativeness of the JLMPS 2010 and especially JLMPS 2016 data after attrition modeling and weighting, we compare in this section key basic labor market and demographic statistics to other contemporaneous Jordanian data sources. We specifically compare our results to the Jordanian EUS, which is the official labor force survey implemented quarterly by DoS. Microdata are available from the EUS through 2016, so we focus our demographic comparisons on this period. We also compare labor market trends and statistics to the Q1 2017 results from published reports, as the majority of JLMPS 2016 fieldwork was carried out in Q1 of 2017. When possible, we also compare our results with the 2015 Population Census. We focus solely on comparisons for Jordanians (data permitting), as the sampling frame for the EUS did not include non-Jordanians until 2017 (Azzeh, 2017).

\subsection{Comparison of demographic characteristics}

The distribution of (5-year) age groups is quite comparable between the JLMPS surveys and other data sources. Figure 1 compares the JLMPS 2010 and EUS 2010. The JLMPS sampled

Figure 1 Comparison of population structure (percentage in 5-year age group), Jordanians, by 2010 data source.

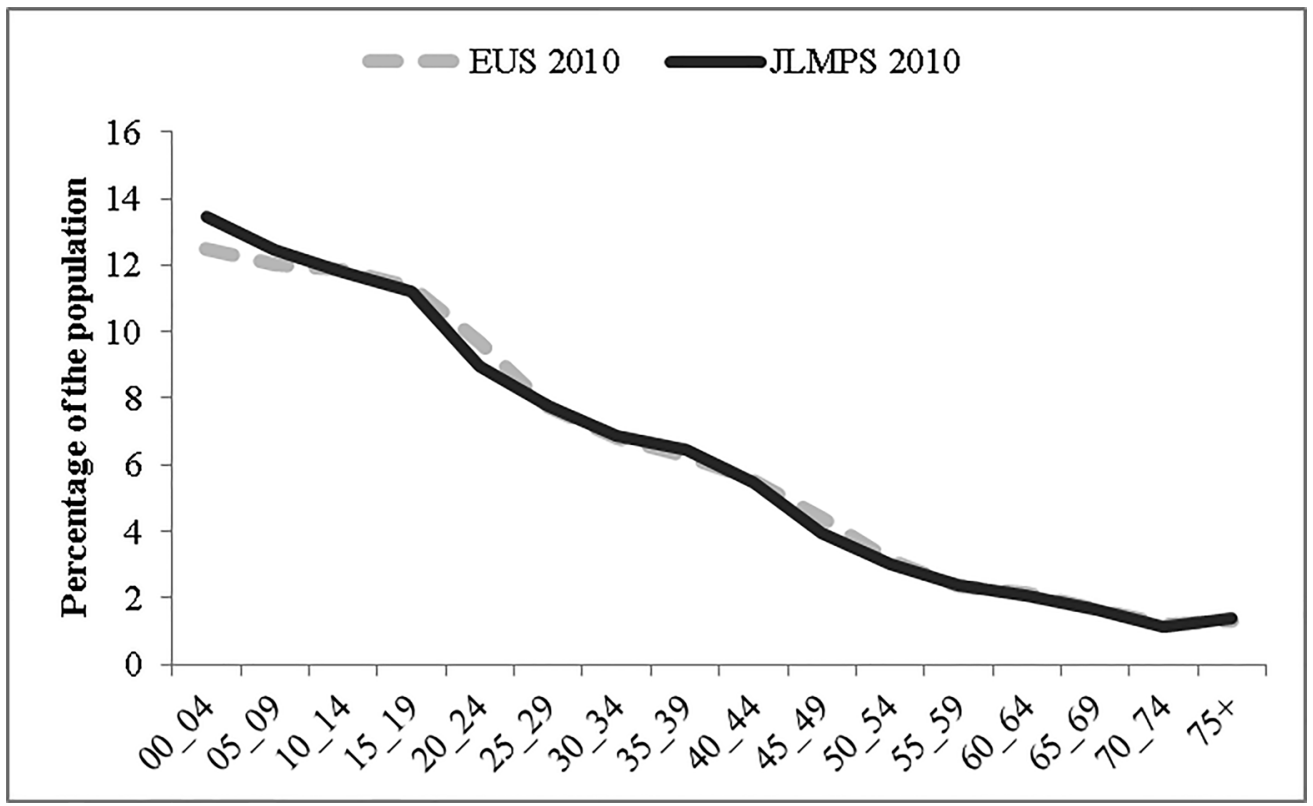

Source: Authors' calculations from EUS 2010 and JLMPS 2010. EUS, Employment and Unemployment Survey; JLMPS, Jordan Labor Market Panel Survey. 
slightly more children in the 0-9 age group than the EUS in 2010. The JLMPS also sampled slightly fewer individuals in the 20-24 age group. The few differences are small and quite plausibly the result of sampling variability. Figure 2 compares the 2015 Population Census and EUS 2016 with JLMPS 2016. The JLMPS 2016 results are quite close to the 2015 Census, closer even than the EUS 2016 (which has a larger sample). The EUS in particular appears to have fewer young children, while both JLMPS 2016 and 2015 Census show a more modest inflection of the population pyramid. ${ }^{20}$

Correctly defining and identifying households is a challenging part of household-based survey fieldwork. JLMPS 2010 shows a comparable distribution of household sizes among Jordanians to the EUS 2010 survey (Figure 3). JLMPS 2010 finds slightly more households with just two people by a percentage point or so, as well as slightly more households with four people compared to the EUS, and slightly fewer households of larger sizes. There are more substantial differences comparing the 2015/2016 data (Figure 4). Here, the Census data are all nationalities living in private households, as household size split by nationality was not available. JLMPS 2016 and the 2015 Census find a similar share of one-person households, but the EUS 2016 captures more one-person households. The JLMPS generally finds more small households than the other two data sources, but the difference with the Census is likely to be driven by Syrian refugees having larger households (Krafft et al., 2019). All three data sources align for households of six and more.

In terms of the marital status of respondents aged 15 years and older, the data sources are quite consistent (Figure 5). The JLMPS 2010 finds one percentage point fewer never married

Figure 2 Comparison of population structure (percentage in 5-year age group), Jordanians, by $2015 / 2016$ data source.

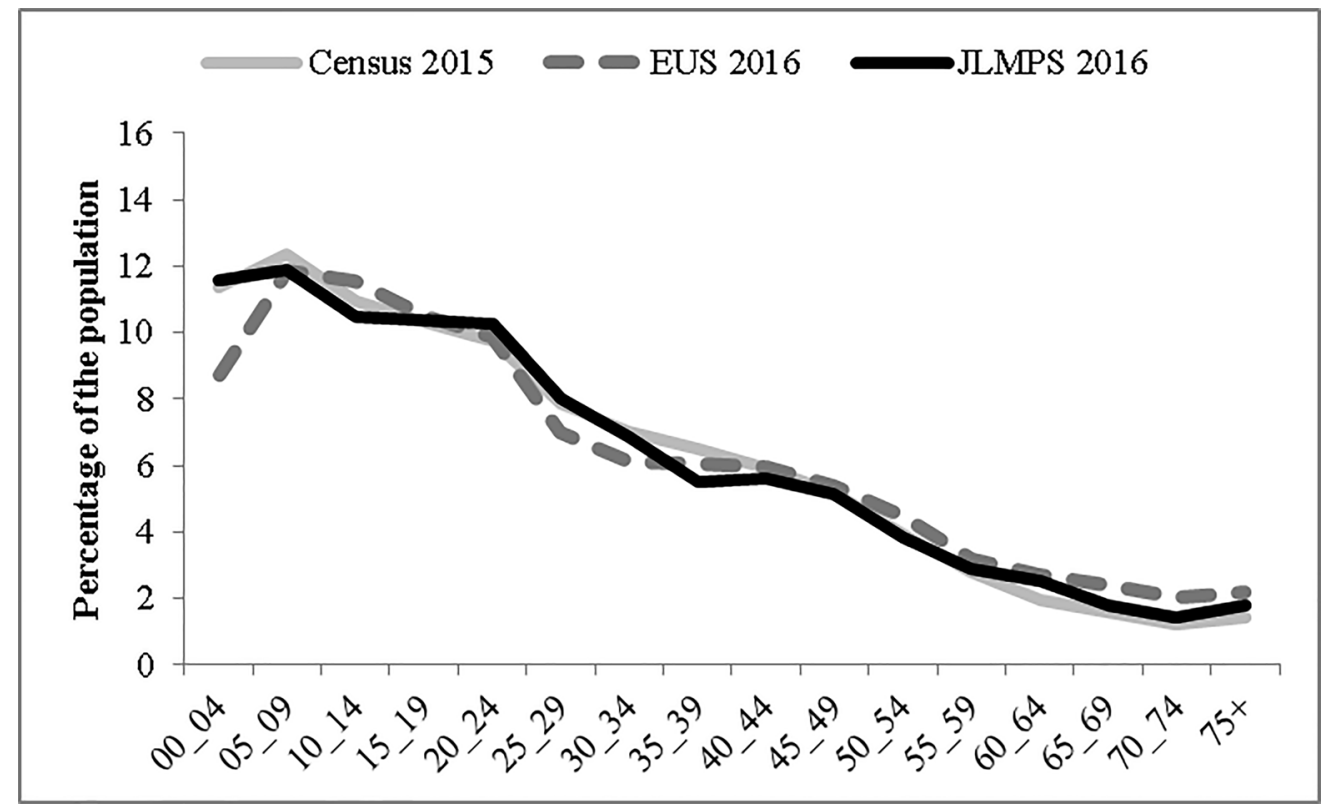

Source: Authors' calculations from EUS 2016 and JLMPS 2016, Census: Department of Statistics (Jordan) (2015a). EUS, Employment and Unemployment Survey; JLMPS, Jordan Labor Market Panel Survey.

20 The changing population structure of Jordan and particularly the resumption of fertility decline after a decade of stall is explored further in Krafft and Sieverding (2018). 
Figure 3 Comparison of household size (percentage of households), Jordanians, by 2010 data source.

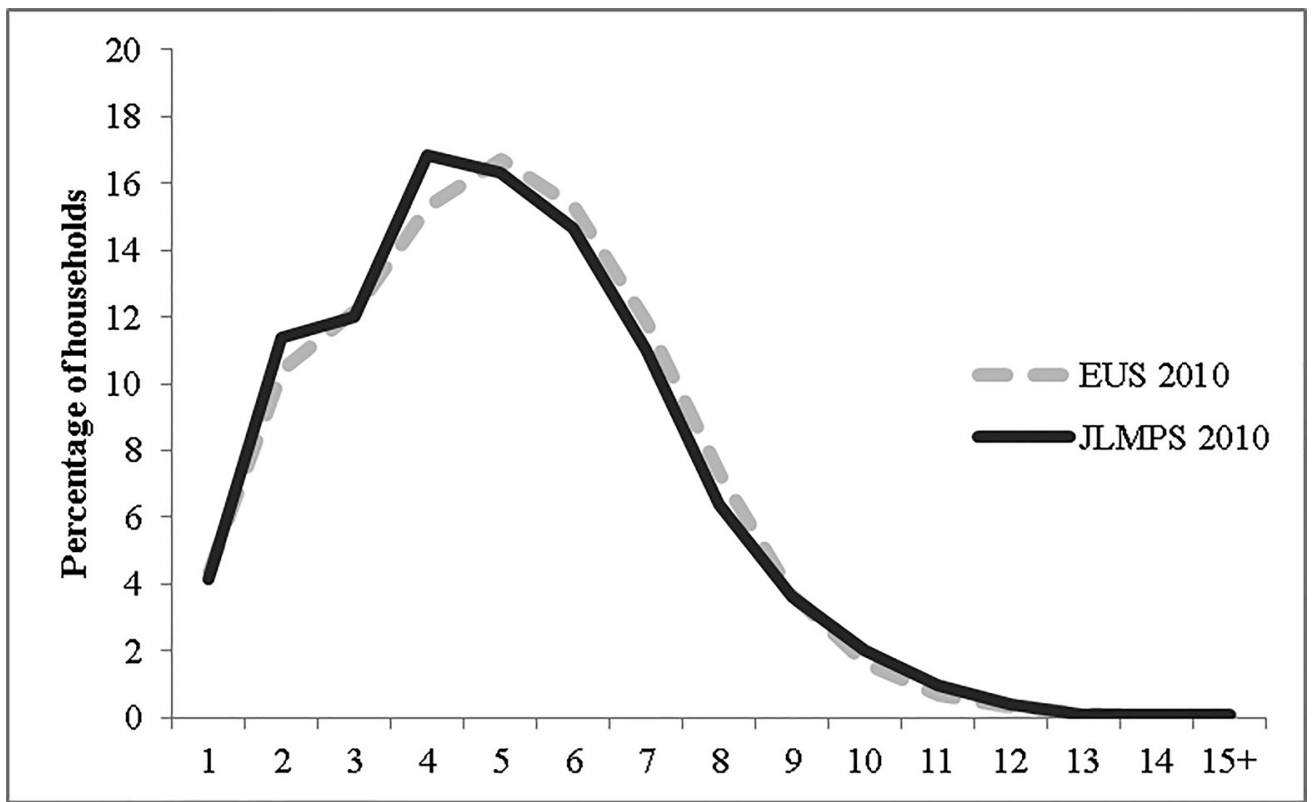

Source: Authors' calculations from EUS 2010 and JLMPS 2010. EUS, Employment and Unemployment Survey; JLMPS, Jordan Labor Market Panel Survey.

Figure 4 Comparison of household size (percentage of households), Jordanians (EUS and JLMPS), all nationalities in private households (Census), by 2015/2016 data source.

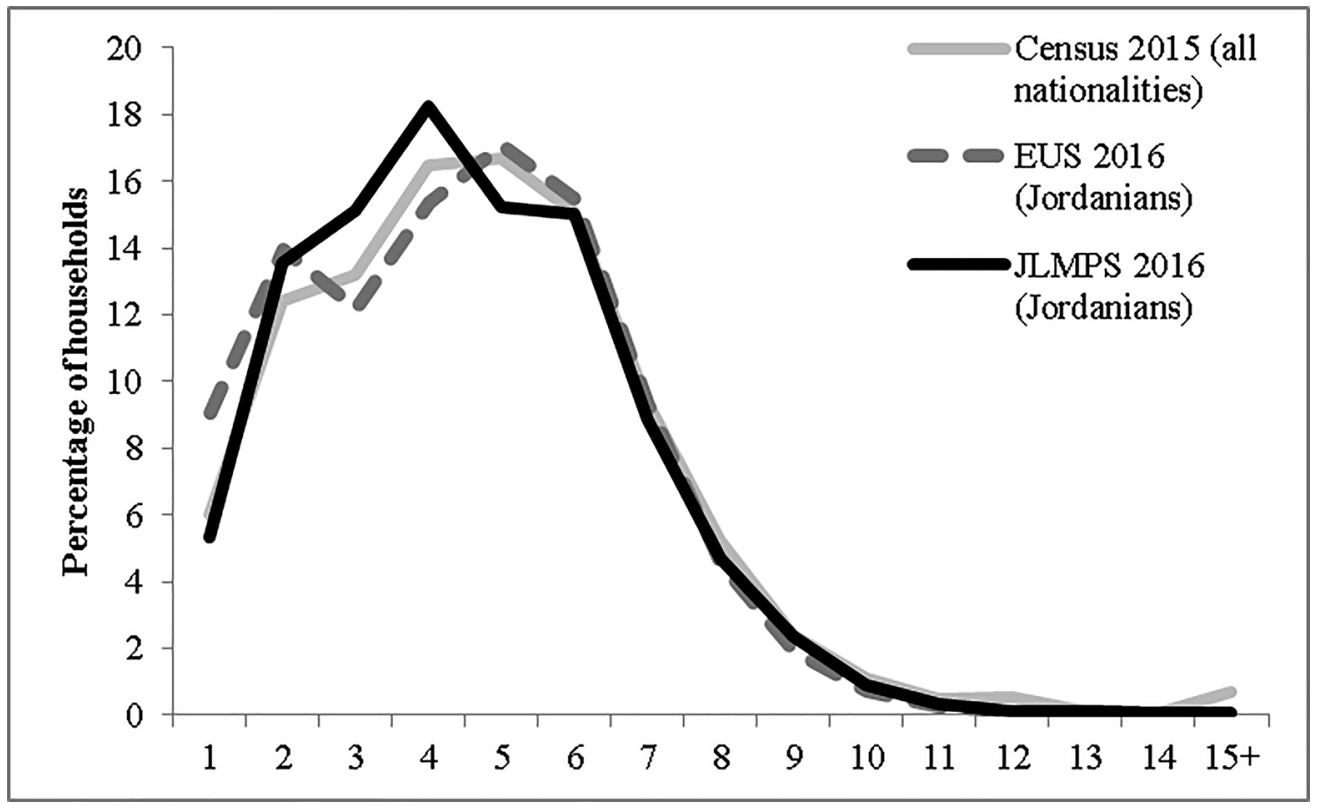

Source: Authors' calculations from EUS 2016 and JLMPS 2016, Census: Department of Statistics (Jordan) (2015d). EUS, Employment and Unemployment Survey; JLMPS, Jordan Labor Market Panel Survey.

individuals and one percentage point more married individuals than the EUS 2010. They identify similar shares of divorced or separated (1\%) and widowed (4\%) individuals. The results over 2015/2016 are slightly more varied, with the 2015 Census and JLMPS 2016 both identifying 
Figure 5 Marital status (percentage) by data source, Jordanians aged 15 years or older.

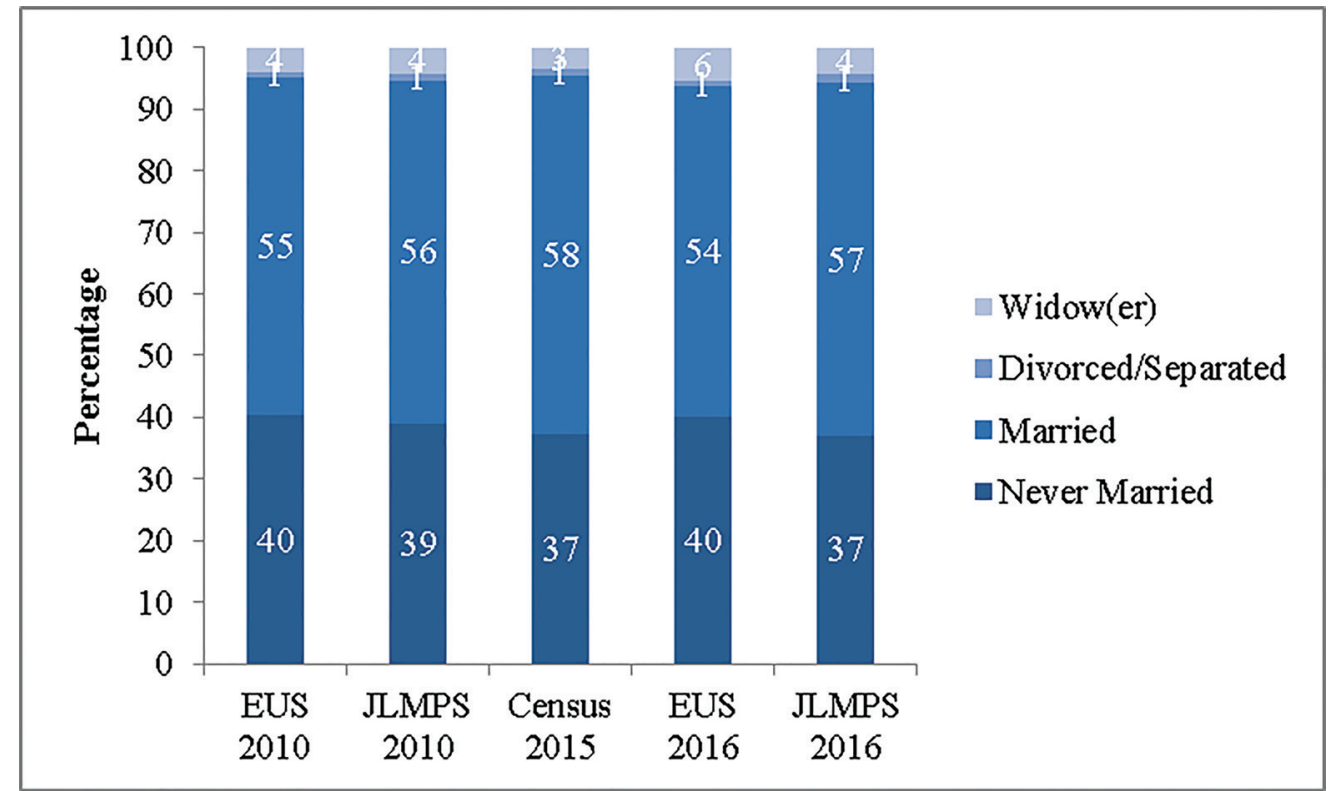

Source: Authors' calculations from EUS 2010 and 2016, JLMPS 2010 and 2016, and Census: Department of Statistics (Jordan) (2015e). EUS, Employment and Unemployment Survey; JLMPS, Jordan Labor Market Panel Survey.

37\% of individuals as never married, but the EUS $201640 \%$ and correspondingly fewer married. While all three sources still find around $1 \%$ of individuals are divorced or separated, fewer are widowed in the 2015 Census (3\%) than JLMPS 2016 (4\%) or EUS 2016 (6\%).

While most demographic indicators are quite close across data sources, there are more substantial differences in terms of educational attainment (Figure 6). The share of the population in the 25-64 age group, of an age to have finished all education, classified as having a post-graduate education is comparable (2-3\%) across time and data sources. The share with a university degree is 16\% in EUS 2010 and 15\% in JLMPS 2010, quite comparable, and rises to $18-19 \%$ across $2015 / 2016$ sources. Similar alignment occurs for 2 -year post-secondary degrees, $12-13 \%$ in 2010 across surveys, and 11\% across 2015/2016 data sources. Where the differences occur are at the secondary and lower levels of education. While the JLMPS 2010 identifies 15\% of Jordanians as secondary educated, the EUS 2010 finds 18\%. The Census in 2015 finds 25\% of Jordanians to have a secondary education, compared with 13\% in the EUS 2016 and 17\% in the JLMPS 2016. Some of these differences may be driven by difficulties in actually classifying attainment, the degree or level completed. The 2015 Census asked attainment categorically (Department of Statistics (Jordan), 2015f), which may have been interpreted as the highest level attended, whereas the JLMPS specifically asks for the highest level successfully completed. Since the secondary examination (tawjihi) pass rate is only 50\% (Ministry of Labor and Ministry of Planning and International Cooperation, 2012), this definitional difference could explain much of the disparity around secondary. Definitional differences, particularly with the change in the structure of basic from 6-year primary and 3-year preparatory to 10 -year basic, may also be contributing to disparate definitions and differences in classifying individuals as basic educated or read and write (which is higher in the JLMPS 2016). Estimates of illiteracy are fairly comparable across JLMPS 2010 (7\%) and EUS 2010 (6\%) as well as the 2015 Census (6\%) and JLMPS 2016 (7\%), with the 
Figure 6. Educational attainment (percentage) by data source, Jordanians aged 25-64 years.

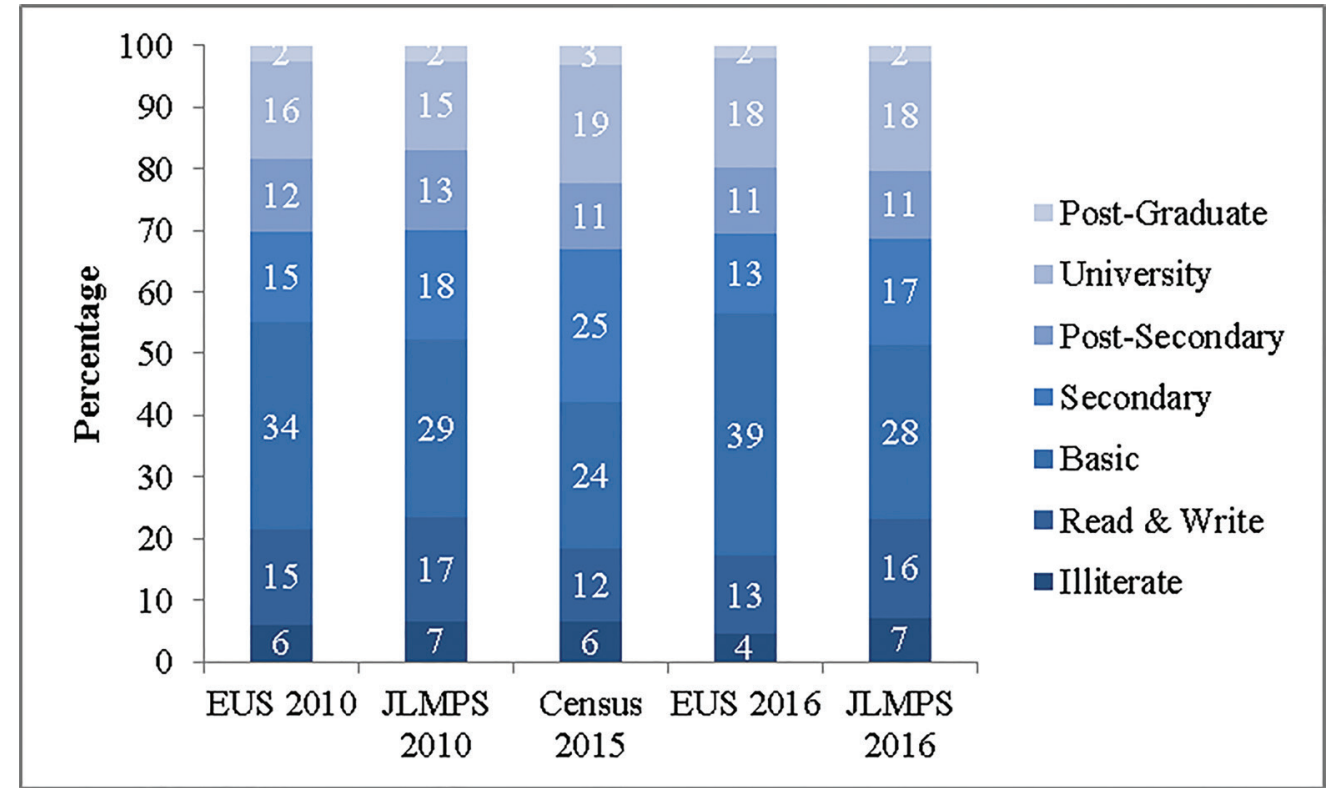

Source: Authors' calculations from EUS 2010 and 2016, JLMPS 2010 and 2016, and Census: Department of Statistics (Jordan) (2015e). EUS, Employment and Unemployment Survey; JLMPS, Jordan Labor Market Panel Survey.

EUS rates in 2016 being lower (4\%). Notably, there is substantial consistency across JLMPS 2010 to JLMPS 2016, after accounting for expected rises in higher education, suggesting that classification and definitional differences are the cause for disparities in educational attainment across sources.

\subsection{Comparison of labor market statistics}

Having established the consistency of the JLMPS data with other Jordanian sources in terms of demographic representation, in this section we turn to analyzing labor market statistics, trends over time, and their alignment. We include 95\% confidence intervals from JLMPS estimates in order to assess whether differences in indicators exceed what we might expect due to sampling variability. We add to our comparisons Q1 of 2017 from the EUS (noted as 2017), since JLMPS 2016 was fielded primarily in 2017 and there appear to be substantial differences in the EUS results between 2016 and Q1 2017.

Figure 7 examines the labor force participation rate among Jordanians by sex. In 2010, the JLMPS detected slightly higher labor force participation than the EUS. The estimates from the EUS for the total rate and the female rate fall within the JLMPS 2010 confidence interval, but the male rate is higher-70\% in the JLMPS 2010 and 67\% in the EUS 2010 although the JLMPS 2010 estimate is not far from the 2009 EUS rate of $69 \%$. Estimates from the 2015 Census appear to be substantially different (much higher) than EUS or JLMPS 2016, which may be due to different definitions or differences in the application of the criteria for participation. The JLMPS 2016 data is in line with the EUS, particularly with the results of Q1 of 2017, which align better with the timing of most of the JLMPS data collection. The total is exactly in line, and while the confidence intervals of the JLMPS 2016 estimates by 
Figure 7. Labor force participation rates (percentage) by sex and data source, Jordanians, 2003-2017.

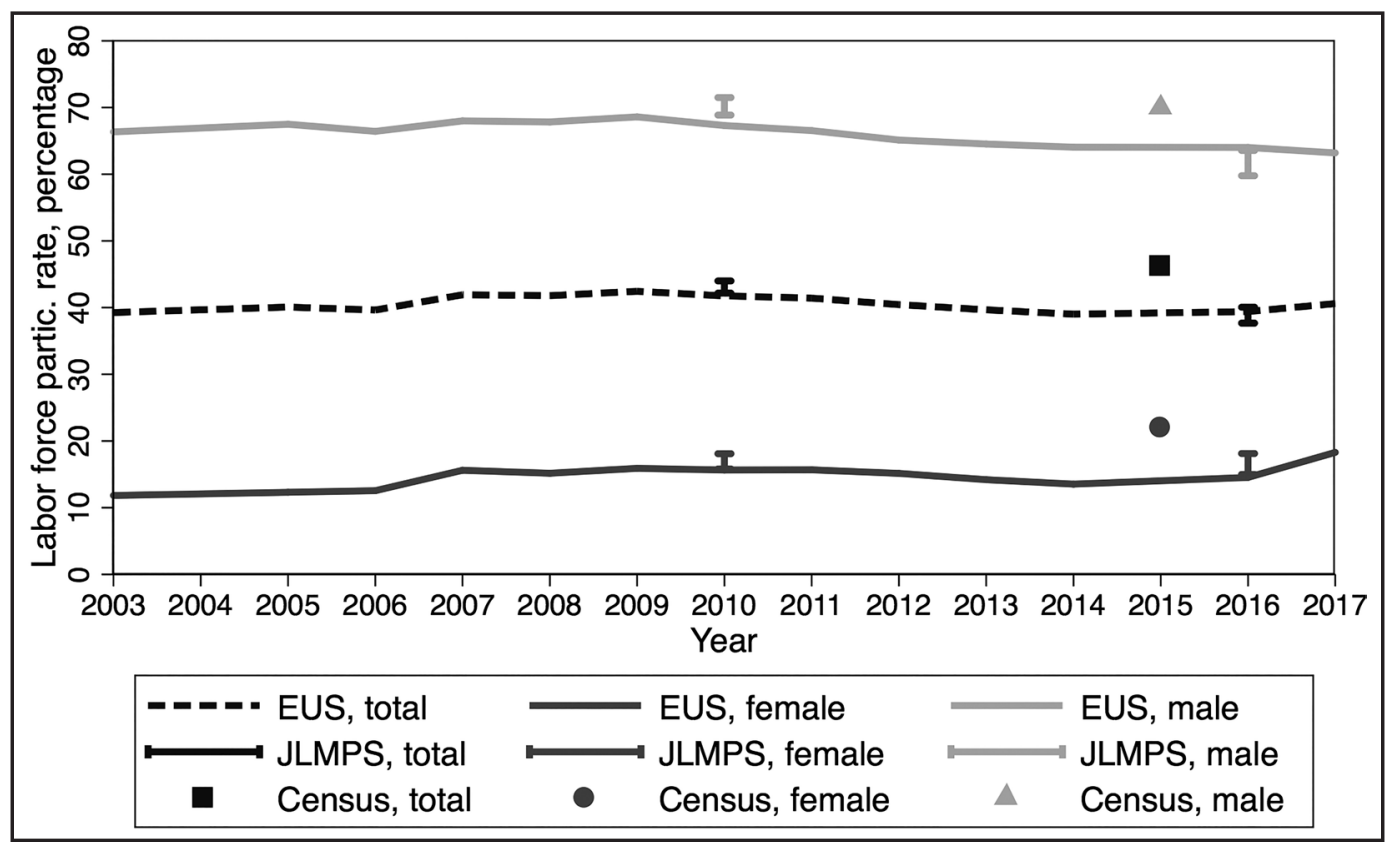

Source: Authors' calculations from EUS 2000-2016, JLMPS 2010 and 2016, and Census: Department of Statistics (Jordan) (2015g), EUS Q1: Department of Statistics (Jordan) (2017). Notes: Age 15-64 years except EUS 2017 Q1 is aged 15 years and older. Bars indicate 95\% confidence intervals from JLMPS, accounting for strata and PSUs under which household was initially sampled. EUS, Employment and Unemployment Survey; JLMPS, Jordan Labor Market Panel Survey; PSUs, primary sampling units.

sex fall slightly below (for men) and above (for women) the EUS estimates for 2016, they include the EUS estimates for Q1 of 2017. Based on EUS data, this was a time of rapid change in labor force participation for Jordanians aged 15 years and older. Male labor force participation increased from 58\% in Q4 2016 to 63\% in Q1 2017, while female rates increased from $13 \%$ to $18 \%$ in the same period (Department of Statistics (Jordan), 2021). After this large jump between Q4 of 2016 and Q1 of 2017, participation rates for Jordanians aged 15 years and older continue along their previous downward trend, falling to 57\% for males and 15\% for females by Q1 2018. We can, therefore, not rule out that the jump observed between Q4 2016 and Q1 2017 was due to changes in data collection and sampling methodology in the EUS. The overall trend, discussed further in Assaad et al. (2019) of a very low and declining rate of labor force participation in Jordan remains a major concern.

Turning to employment rates (Figure 8), we see similar patterns as with labor force participation. JLMPS 2010 has a higher estimate of the employment rate for men than EUS 2010, and the total as well as the male rate has confidence intervals that do not include the EUS 2010 estimate. The census again has higher employment rates than the EUS 2016 or JLMPS 2016. JLMPS 2016 confidence intervals for men and women include the EUS 2016 estimates, although the total is a little low, and the JLMPS 2016 estimates are closer to the EUS Q1 2017 estimates.

Since the unemployment rate is calculated as a share of the labor force, necessarily the JLMPS estimates have larger standard errors and confidence intervals for unemployment than for employment or labor force participation (Figure 9). Comparing 2010 data, the 
Figure 8. Employment rates (percentage) by sex and data source, Jordanians, 2003-2017.

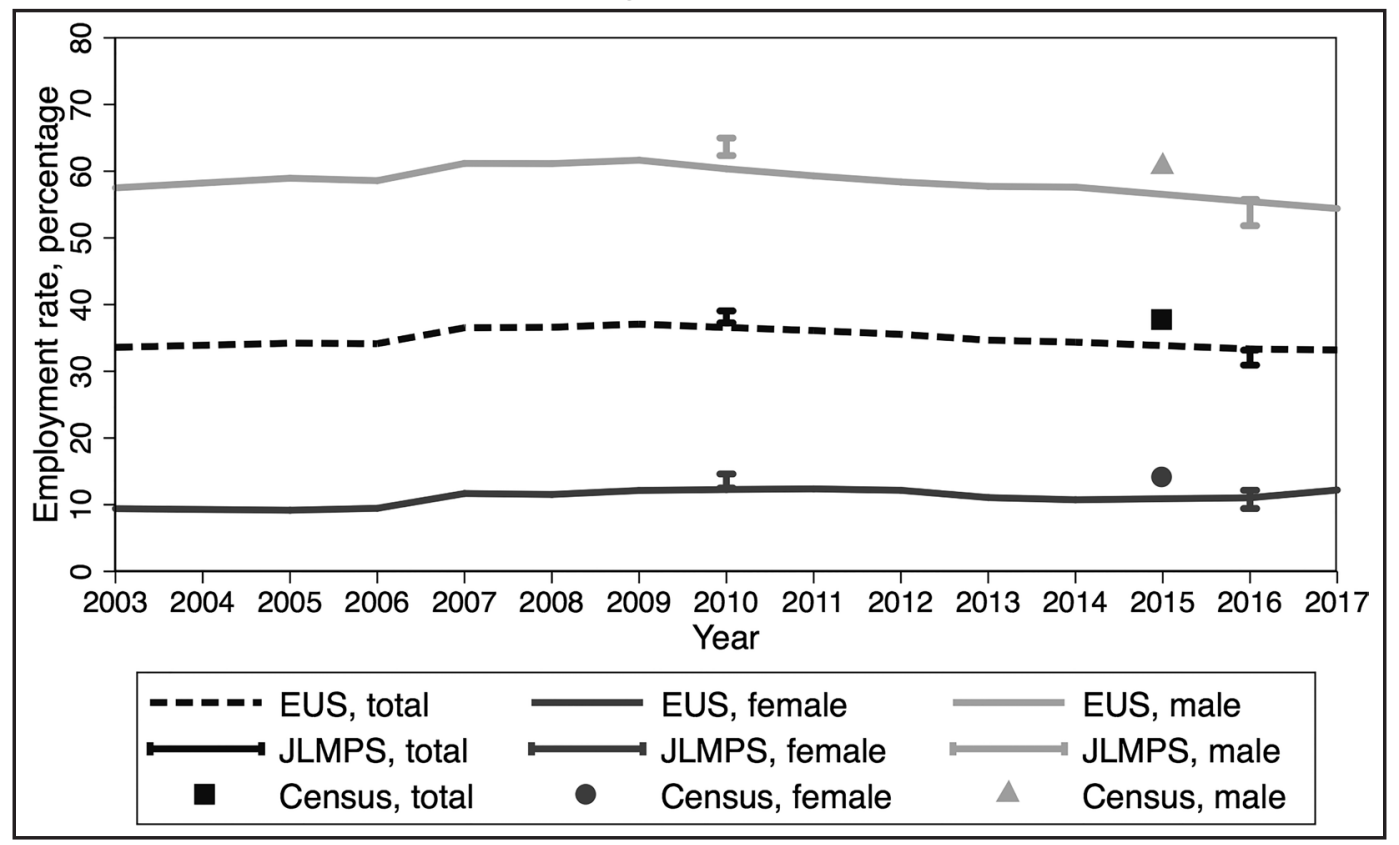

Source: Authors' calculations from EUS 2000-2016, JLMPS 2010 and 2016, and Census: Department of Statistics (Jordan) (2015g), EUS Q1: Department of Statistics (Jordan) (2017). Notes: Age 15-64 years except EUS 2017 Q1 is aged 15 years and older. Bars indicate 95\% confidence intervals from JLMPS, accounting for strata and PSUs under which household was initially sampled. EUS, Employment and Unemployment Survey; JLMPS, Jordan Labor Market Panel Survey; PSUs, primary sampling units.

Figure 9. Unemployment rates (percentage) by sex and data source, Jordanians, 2003-2017.

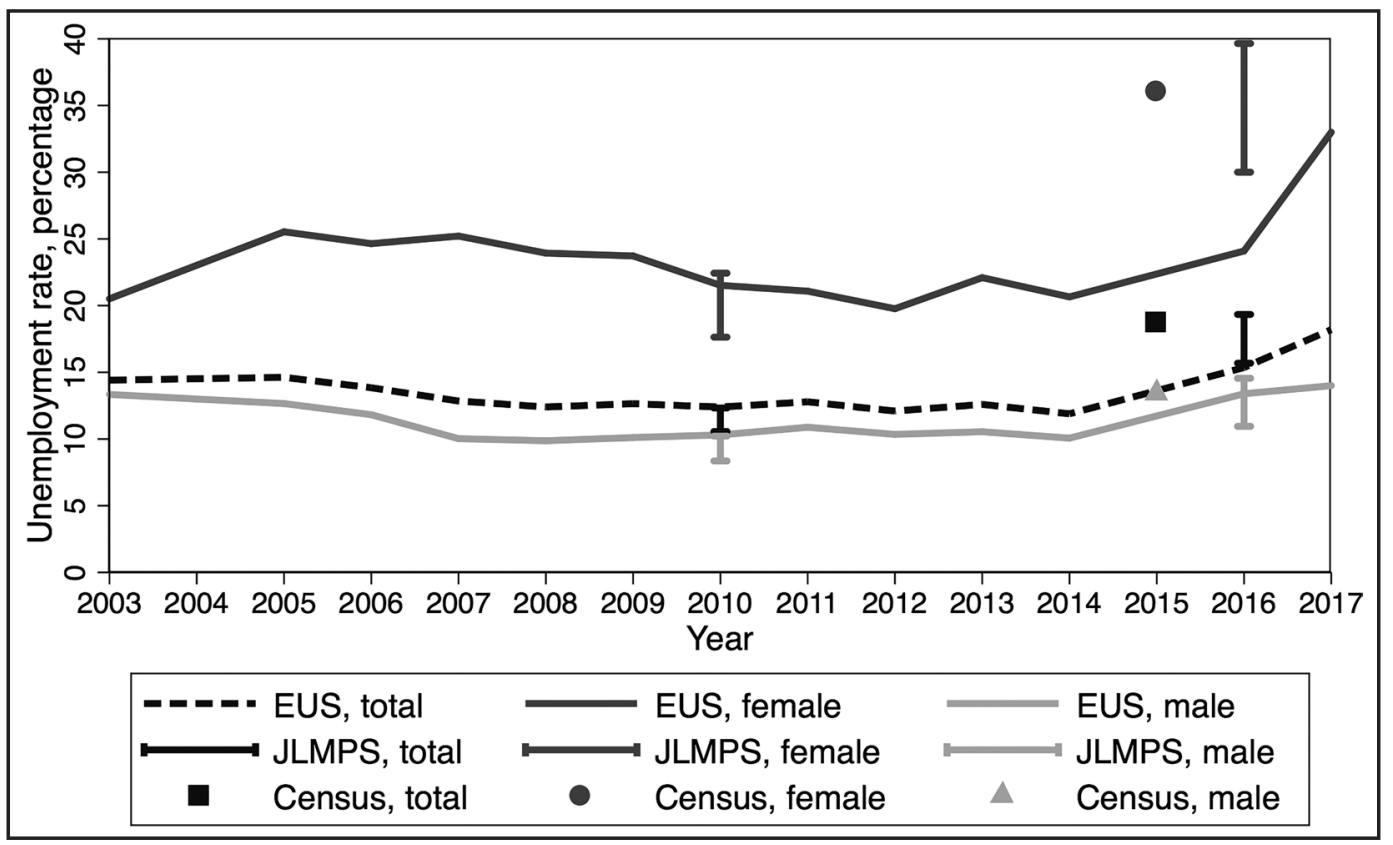

Source: Authors' calculations from EUS 2000-2016, JLMPS 2010 and 2016, and Census: Department of Statistics (Jordan) (2015g), EUS Q1: Department of Statistics (Jordan) (2017). Notes: Age 15-64 years except EUS 2017 Q1 is aged 15 years and older. Bars indicate 95\% confidence intervals from JLMPS, accounting for strata and PSUs under which household was initially sampled. EUS, Employment and Unemployment Survey; JLMPS, Jordan Labor Market Panel Survey; PSUs, primary sampling units. 
JLMPS 2010 estimates of unemployment are slightly lower and have confidence intervals that just marginally exclude the EUS estimates for men and the total, but include the EUS estimates for women. The EUS 2016 estimates of unemployment are not included in the JLMPS 2016 confidence intervals for women or the total; however, the JLMPS 2016 confidence intervals include the 2015 Census estimate and the 2017 Q1 estimate for all groups, a high rate of unemployment for women at around 35\% in the JLMPS 2016. Overall, the JLMPS results appear to be very close to other estimates, especially those of Q1 2017 of the EUS, which was implemented at about the same time. This was a period of rapid change in unemployment rates for Jordanian women. While the unemployment rate for men remained stable at $14 \%$ for men between Q4 2016 and Q1 2017 according to the EUS, it jumped sharply for women from $25 \%$ to $33 \%$, in line with the JLMPS estimate. The overall unemployment rate also increased by 2 percentage points. The increase in unemployment for women continued through Q2 2017, when it reached 34\% before declining to 28\% by Q4 2017 (Department of Statistics (Jordan), 2021). Again, we cannot rule out that the jump from Q4 2016 to Q1 2017 in the female unemployment rate in the EUS is due to some change in methodology.

\section{Comparison of JLMPS panel and retrospective data}

As an ongoing survey series, the LMPSs provide an important opportunity to study and improve questionnaire design. Past research used multiple waves of the ELMPS and compared the contemporaneous panel data from previous waves to reported retrospective status (from the labor history module) (Assaad et al., 2018). While durable employment statuses, such as public sector work, were reported with a high degree of accuracy, more transitory statuses, and particularly unemployment, often went under-detected or misreported. As a result, starting with JLMPS 2016 we revised the questionnaire design to specifically ask about periods of non-employment.

For those who never worked, we collected retrospective data on ever seeking work and the dates of such job-seeking. For those who had ever worked and thus answered the labor history module, we asked about whether there was a period of non-employment after school exit but before the first job, and if so, whether the respondent was wanting and ready to work during that time, as well as whether they searched for work. Respondents were then asked about their first job, its dates, and details. At the end of the series of questions on the first job, they were asked if they had left the job. While in previous LMPSs we then asked about subsequent statuses, which could be unemployment or non-employment, because these were under-reported, we suspected that enumerators and/or respondents failed to consider non-employment as a labor market status. We therefore added questions at the end of each job as to whether there was a period of non-employment lasting 6 months or more, and if so, the dates, as well as whether the respondent had wanted to work in that period and whether the respondent was searching in that period.

This section investigates the effects of these improvements on data accuracy using the JLMPS 2016 and 2010 waves. The new and improved labor history data from 2016 were used to construct the retrospective report of 2010 status. This retrospective status is then compared to the status reported contemporaneously at the time of JLMPS 2010 fielding. Figure 10 compares 
Figure 10. Labor market status, as reported retrospectively for 2010 from 2016 data, by sex and contemporaneous status for 2010, individuals aged 20-44 years in 2010 and present in both waves (percentage).

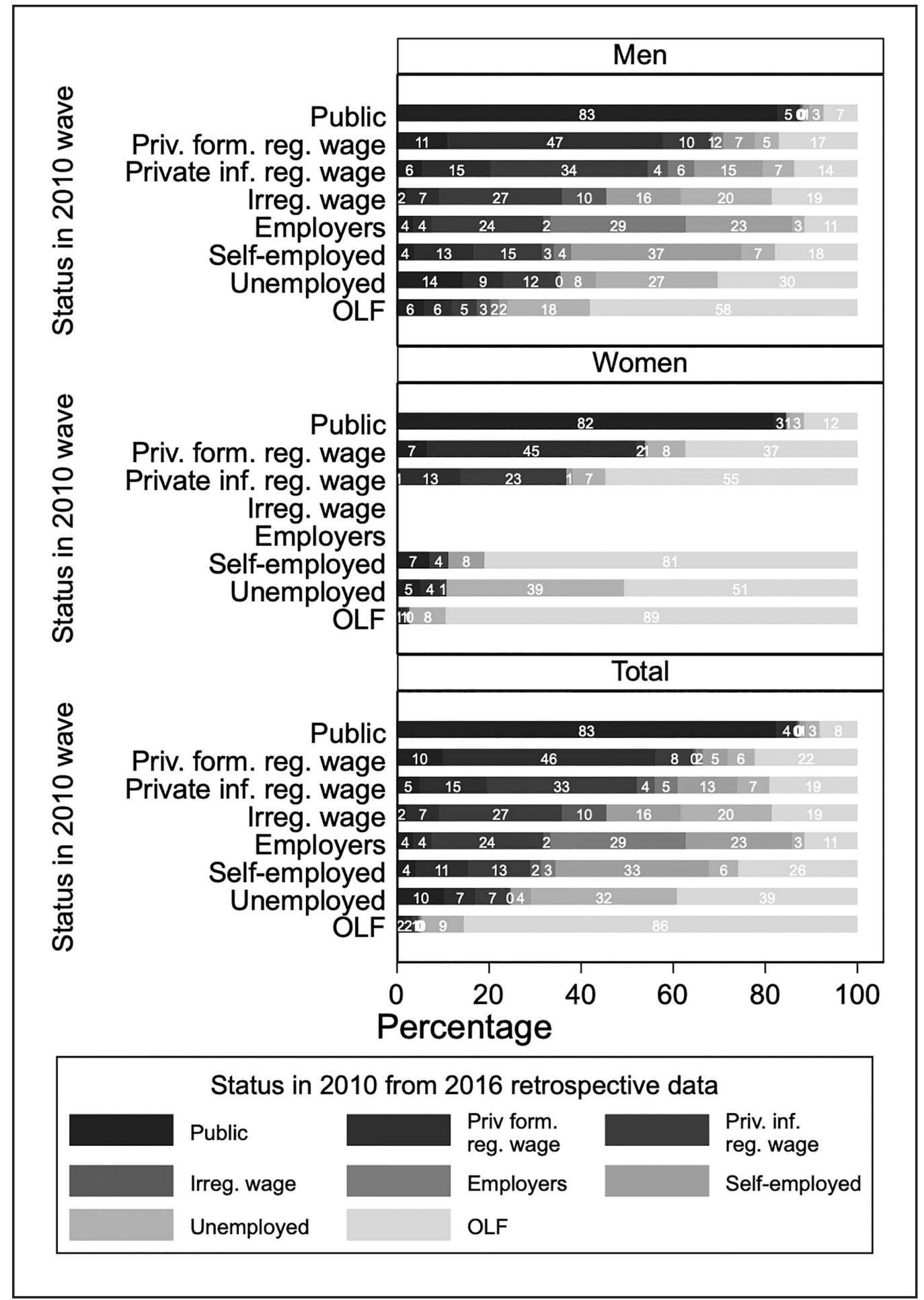

Source: Authors' calculations from JLMPS 2010 and JLMPS 2016 retrospective data.

Notes: Due to $\mathrm{N}<20$ in 2010 data, unpaid family workers combined with self-employed for both men and women; for women irregular wage workers combined with private informal regular and employers combined with self-employed. JLMPS, Jordan Labor Market Panel Survey. 
these statuses, ${ }^{21}$ by sex, focusing on those aged 20-44 years during the 2010 wave, so during prime insertion and working years.

As was found by past research, more durable statuses are reported more consistently (Assaad et al., 2018). For example, 84\% of those who reported being in the public sector contemporaneously in 2010 also did so in the 2016 retrospective data. A further $4 \%$ stated that they were in private formal wage employment, which suggests some potential confusion of sectors or dates of job transitions. Almost none reported informal statuses or employer or self-employed work, retrospectively. A further 3\% reported being unemployed and $7 \%$ being out of the labor force. Statuses that are more dynamic (Assaad and Salemi, 2019) have less consistency. For instance, among those who were private formal regular wage workers in 2010, $49 \%$ reported being so in the 2016 retrospective data for 2010, with the next most common employment status being public sector work (11\%) followed by private sector informal work (9\%), potentially confusion around sector and formality or transitions. Around $17 \%$ reported being out of the labor force, primarily due to women not reporting private sector work in their labor market histories. Likewise, being an employer was reported accurately only $29 \%$ of the time, but many of those who were employers in 2010 reported, retrospectively, being self-employed in the 2016 data (23\%), likely due to transitions between having employees or not (and thus being an employer or self-employed) that are imprecisely remembered or measured. Out of labor force in 2010 was the most consistently reported status (85\%), and the next most commonly reported was unemployment (9\%). While only $33 \%$ of those who were unemployed in 2010 reported being so in the retrospective data for 2010 in 2016, this is a substantial improvement from previous designs. In comparing ELMPS 2006 data with the ELMPS 2012 retrospective data for 2006, only 13\% of the unemployed in 2006 reported being so in the 2012 retrospective data for 2006 (Assaad et al., 2018). The improved design of the labor history and specific non-employment questions yielded more consistent data.

Further analyses (Figure 11) suggest major improvements in detecting aggregate patterns with the retrospective data, particularly for women. The share out of the labor force for women $(76 \%)$ is consistent across the contemporaneous and retrospective data. For comparison, in the ELMPS, while contemporaneously $66 \%$ of women were out of the labor force in 2006, the retrospective data from 2012 for 2006 indicated that 77\% were (Assaad et al., 2018). With JLMPS 2016, slightly fewer men are out of the labor force, in the contemporaneous (11\%) than retrospective (16\%) data. Retrospective data now appear to be, if anything, over-detecting unemployment, specifically for women (6\% share of the population in the contemporaneous data and $9 \%$ in the retrospective). We may be detecting periods of non-employment during which women wanted to work and eventually gave up within the retrospective data as unemployment, with the contemporaneous data capturing their status after giving up as out of the labor force. Private sector informal wage work is a bit under-detected in retrospective data, for example, $18 \%$ in contemporaneous and $13 \%$ in retrospective data among men, but other employment statuses such as employer and self-employed are detected fairly consistently in the aggregate. Comparing the aggregate results in Figure 11 with the reports in Figure 10 suggests that we have made major improvements in detecting different types of statuses compared to

21 The figure uses the broad definition of unemployment, not applying the search requirement, since it had a specific fourweek window in the JLMPS contemporaneous data that is not precisely measurable in the retrospective data. 
Figure 11. Labor market status, as reported contemporaneously for 2010 and as reported retrospectively for 2010 from 2016 data, by sex, individuals aged 20-44 years in 2010 and present in both waves (percentage).

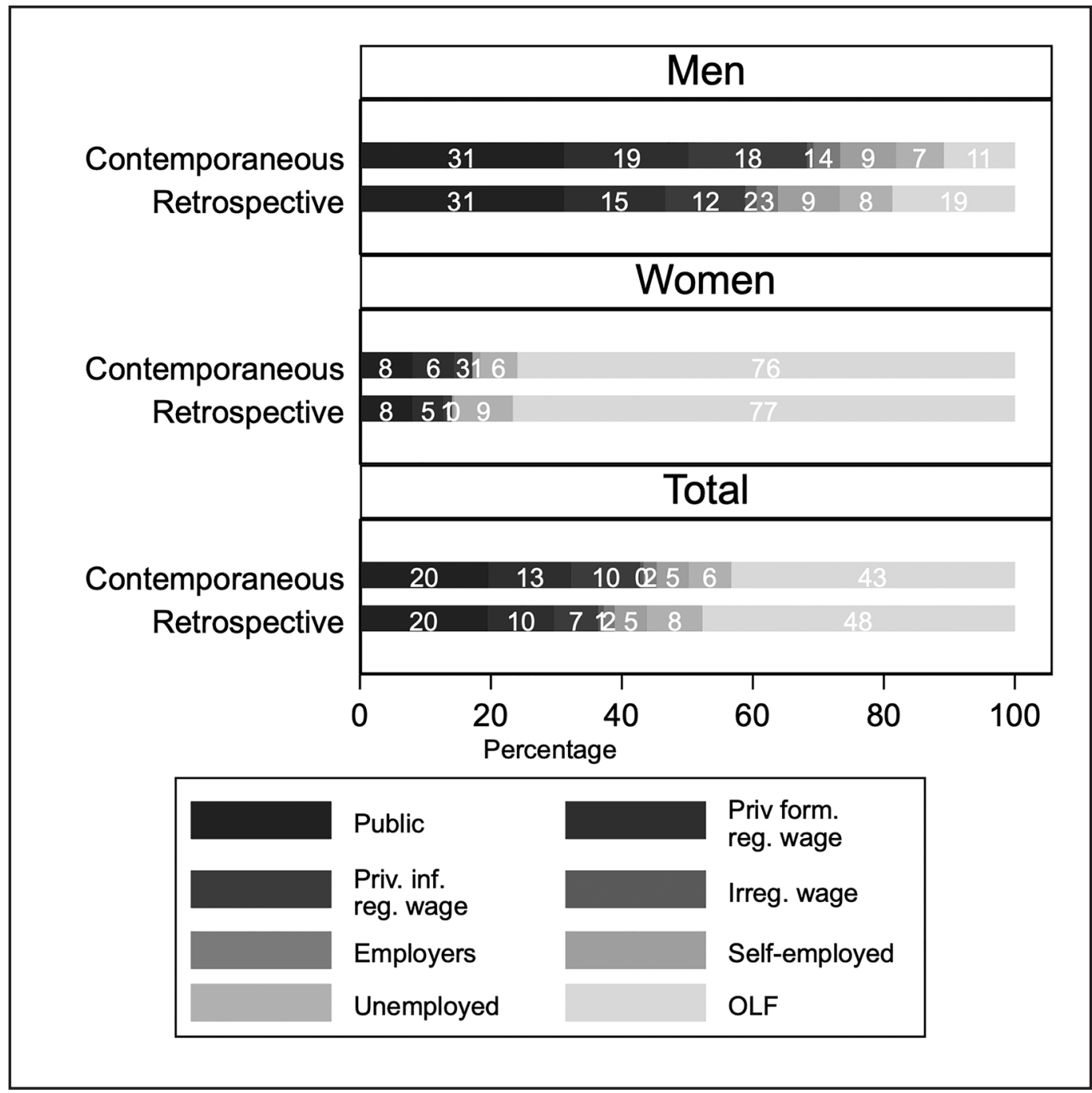

Source: Authors' calculations from JLMPS 2010 and JLMPS 2016 retrospective data.

Notes: Due to $N<20$ in 2010 data, unpaid family workers combined with self-employed for both men and women; for women irregular wage workers combined with private informal regular and employers combined with self-employed. JLMPS, Jordan Labor Market Panel Survey.

past designs (Assaad et al., 2018). However, precision of dates in recall may remain an issue and an important area for future improvements.

\section{Conclusions}

We discussed in this paper the design and implementation of the second wave of the JLMPS, which was implemented in late 2016 and early 2017 and which we refer to as JLMPS 2016. The period between the first and second waves - 2010 to 2016 - was a period of substantial turbulence in Jordan, as the country was buffeted by the powerful forces unleashed by the Arab Spring, not least of which was the large influx of Syrian refugees and a major slowdown 
in economic activity. The paper highlights the added value that the JLMPS provides for the analysis of these turbulent times in Jordan's history. Some key analyses were already presented in an edited volume (Krafft and Assaad 2019) and in a number of research papers cited in the "Introduction," but the richness of the data permits a great deal more to be done. We hope that this paper will serve as a reference to those who want to use the publicly available microdata to conduct more in-depth studies as well as comparative studies with the other countries for which LMPSs are available, namely Egypt and Tunisia, and hopefully, soon, Sudan.

In order to capture the effects of the large migrant and refugee flows, the survey design team added a sizable refresher sample, which oversampled neighborhoods (including refugee camps) with large proportions of non-Jordanian households. This sampling strategy was particularly successful in achieving a good representation of the Syrian population, something that was never previously achieved in nationally representative household surveys in Jordan. The JLMPS 2016 is thus the first data to allow researchers to assess the labor market status of Syrian refugees in Jordan.

The representation of other nationality groups, such as Egyptians, was also substantially improved over previous household surveys, but because many Egyptian migrants live in group quarters or on job sites, they probably remain somewhat under-represented. The sizeable sample of migrants and Syrians is already facilitating important new research (El-Mallakh and Wahba, 2018; Fallah et al., 2019; Krafft et al., 2019; Malaeb and Wahba, 2018, 2019; Sieverding et al., 2020, 2018). Important findings include the low employment rates of Syrians (36\% for men and $2 \%$ for women) and their continuing informality, despite the availability of work permits (Assaad et al., 2019; Krafft et al., 2019). We look forward to future findings using this important data public good.

Comparing the JLMPS with the EUS and Census confirmed that (after the application of weights) we have a comparable sample to other data sources. The demographics of the samples in 2010 and 2016 are quite similar to other sources in terms of age distribution, household size, and marital status. Definitional differences likely led to disparate classifications of midlevel educational attainment, but higher education and illiteracy are consistent. In terms of key labor market indicators, the JLMPS was generally quite close to other contemporaneous statistics, with differences often in the range of sampling variability. The JLMPS results in 2016 are particularly close to those of EUS 2017 Q1, when the JLMPS was fielded. The results captured the worsening labor market conditions in Jordan, and particularly the rise in female unemployment, quite consistently.

\subsection{Limitations}

As with any longitudinal survey, attrition from one wave to another is an issue. We consider in this paper two types of attrition. Type I is when a household interviewed in the previous wave is not found in its entirety and Type II is when individuals who are no longer in the household due to splits cannot be found. The probability of both types of attrition was relatively high in JLMPS 2016 at 38.1\% (Type I) and 50.5\% (Type II). Factors that contributed to higher Type I attrition presumably include the relatively high proportion of non-national households living in Jordan and the generally higher residential mobility of households in Jordan (moves and mobility are linked to attrition in other surveys as well (Thomas et al., 2012; Vaillant, 
2013)). The relatively high Type II attrition resulted from fieldwork-related issues at the fielding stage, which prevented individuals newly identified to be splits from being tracked. In any case, modeling of the two types of attrition reveals that both were for the most part random, although some observables systematically affected attrition. For instance, being in the highest urban decile of wealth increased attrition of both types, a pattern that can be linked to the higher refusal rate among wealthy households (urban and higher income individuals are more likely to attrite in other surveys as well (Himelein, 2014; Thomas et al., 2012)). Other correlates of Type I attrition were also fairly predictable, such as the higher attrition of all male households, which tend to be temporary in nature, and the higher attrition among households that rent as opposed to own their dwelling. Households with more educated household heads also had higher attrition rates, presumably because of their higher residential mobility. Type II attrition was driven in part by location, with splits from smaller urban areas being easiest to locate. Females were easier to locate in general when they split, but this does not apply to young females (25-34 years) who presumably move from their natal households when they marry. Finally, private sector workers appear to be more difficult to locate if they split than public sector workers. We created both panel and cross-sectional weights to account for these differential rates of attrition and maintain the representativeness of our sample, but it should be kept in mind that attrition based on unobservables can continue to be a source of bias.

Although the JLMPS included important innovations in the labor market history, a number of challenges arose in fieldwork that are limitations of the data and point to important directions for future LMPSs. First, we are no longer undertaking separate enumeration rounds, as this again led to attrition and added costs. In ELMPS 2018, eschewing a separate enumeration round substantially reduced attrition (Krafft et al., 2019). The software we used in JLMPS 2016 was limited in its ability to handle multilevel information, requiring separate household and individual data and leading to a non-representative sample of household enterprises in JLMPS 2016. Going forward, we are using the ODK-X tools (Brunette et al., 2017) that allow for multilevel data and appropriate skips and constraints far more effectively. This will also allow us to ask who in the household engaged in various enterprises, improving our detection of women's work (Krafft et al., 2019).

For future LMPSs, we will also be ensuring that both men and women are asked about gender role attitudes, as well as adding a brief contraception and pregnancy question series to the fertility history. Given the importance of the "second shift" to women's challenges reconciling market work and domestic responsibilities (Assaad et al., 2017; ERF and UN Women, 2020; Selwaness and Krafft, 2021), we recommend adding a 24-h our time diary to future LMPSs. In light of both the ongoing struggles in the MENA region and especially Jordan to integrate youth into the labor market, challenges only exacerbated by the COVID-19 pandemic, we also recommend adding questions on engagement with active labor market policies, trainings, internships, and apprenticeships.

\subsection{Future directions for research}

The comparability of the JLMPS data to other statistics on Jordanians makes clear that the results of the survey are generalizable, and the rich, detailed data on a variety of subjects represent the Jordanian population well. The comparisons of the data from 2010 and the 2016 
retrospective data about 2010 show substantial improvements in the questionnaire design and resulting retrospective data quality. Additionally, the over-sampling of non-Jordanians in the refresher sample of 2016 provides a unique opportunity to study both refugees and other migrant groups in Jordan. Already, the data provide important insights into issues as diverse as the well-being of refugees (Krafft et al., 2019), the impact of the refugee influx on Jordan's labor and housing markets (Al-Hawarin et al., 2021; Fallah et al., 2019), social insurance reforms (Alhawarin and Selwaness, 2019), and marriage and fertility trends (Krafft and Sieverding, 2018; Sieverding et al., 2019). We look forward to seeing additional research with the JLMPS as it is now publicly available, and comparing Jordan with the other countries with LMPSs.

\section{References}

Al-Amaera, Ahmad (2019): "The Impact of Arab Spring on Tourism Sector in Jordan." European Journal of Business and Management 11(26), 1-12.

Al-Hawarin, Ibrahim; Ragui Assaad; Ahmed Elsayed (2021): "Migration Shocks and Housing: ShortRun Impact of the Syrian Refugee Crisis in Jordan." Journal of Housing Economics 101761, https://doi. org/10.1016/j.jhe.2021.101761.

Alhawarin, Ibrahim; Irene Selwaness (2019): "The Challenges of Social Security Coverage and Early Retirement in Jordan: What Happened after the 2010 Pension Reform?” in: Krafft, Caroline; Ragui Assaad (eds.), The Jordanian Labor Market Between Fragility and Resilience. Oxford, UK: Oxford University Press, 313-340.

Alrababa'h, Ala; Andrea Dillon; Scott Williamson; Jens Hainmueller; Dominik Hangartner; Jeremy Weinstien (2021): "Attitudes toward Migrants in a Highly-Impacted Economy: Evidence from the Syrian Refugee Crisis in Jordan." Comparative Political Studies 54(1), 33-76.

Amer, Mona (2014): "The School-to-Work Transition of Jordanian Youth," in: Assaad, Ragui (ed.), The Jordanian Labour Market in the New Millenium. Oxford, UK: Oxford University Press, 64-104.

Amer, Mona (2019): "School-to-Work Transition in Jordan, 2010-2016," in: Krafft, Caroline; Ragui Assaad (eds.), The Jordanian Labor Market Between Fragility and Resilience. Oxford, UK: Oxford University Press, 225-258.

Amer, Mona; Marian Atallah (2019): "The School to Work Transition and Youth Economic Vulnerability in Egypt.” Economic Research Forum Working Paper Series No. 1353. Cairo, Egypt.

Arayssi, Mahmoud; Ali Fakih; Nathir Haimoun (2019): "Did the Arab Spring Reduce MENA Countries' Growth?" Applied Economics Letters 26(19), 1579-1585.

Assaad, Ragui (2008): "Unemployment and Youth Insertion in the Labor Market in Egypt," in: Kheir-El-Din, Hanaa; Heba El-Laithy (eds.), The Egyptian Economy: Current Challenges and Future Prospects. Cairo, Egypt: American University in Cairo Press, 133-178.

Assaad, Ragui (ed.) (2014): The Jordanian Labour Market in the New Millenium. Oxford, UK: Oxford University Press.

Assaad, Ragui; Ghada Barsoum (2000): "Egypt Labor Market Survey, 1998: Report on the Data Collection and Preparation." Cairo, Egypt.

Assaad, Ragui; Christine Binzel; May Gadallah (2010): "Transitions To Employment and Marriage Among Young Men in Egypt." Middle East Development Journal 2(1), 39-88.

Assaad, Ragui; Samir Ghazouani; Caroline Krafft; Dominique J. Rolando (2016): "Introducing the Tunisia Labor Market Panel Survey 2014." IZA Journal of Labor \& Development 5(15), 1-21.

Assaad, Ragui; Thomas Ginn; Mohamed Saleh (2018): "Impact of Syrian Refugees in Jordan on Education Outcomes for Jordanian Youth.” Economic Research Forum Working Paper Series No. 1214. Cairo, Egypt.

Assaad, Ragui; Rana Hendy; Moundir Lassassi; Shaimaa Yassin (2020): "Explaining the MENA Paradox: Rising Educational Attainment, Yet Stagnant Female Labor Force Participation.” Demographic Research 43(28), 817-850.

Assaad, Ragui; Rana Hendy; Chaimaa Yassine (2014): "Gender and the Jordanian Labor Market." in: Assaad, Ragui (ed.), The Jordanian Labour Market in the New Millennium. Oxford, UK: Oxford University Press, 105-143.

Assaad, Ragui; Caroline Krafft (2013): "The Egypt Labor Market Panel Survey: Introducing the 2012 Round." IZA Journal of Labor \& Development 2(8), 1-30. 
Assaad, Ragui; Caroline Krafft (2015): “Is Free Basic Education in Egypt a Reality or a Myth?" International Journal of Educational Development 45, 16-30.

Assaad, Ragui; Caroline Krafft (2021): "Excluded Generation: The Growing Challenges of Labor Market Insertion for Egyptian Youth." Journal of Youth Studies 24(2), 186-212.

Assaad, Ragui; Caroline Krafft; Caitlyn Keo (2019): "The Composition of Labor Supply and Its Evolution from 2010 to 2016 in Jordan," in: Krafft, Caroline; Ragui Assaad (eds.), The Jordanian Labor Market Between Fragility and Resilience. Oxford, UK: Oxford University Press, 11-42.

Assaad, Ragui; Caroline Krafft; Irene Selwaness (2017): "The Impact of Marriage on Women's Employment in the Middle East and North Africa." Economic Research Forum Working Paper Series No. 1086. Cairo, Egypt.

Assaad, Ragui; Caroline Krafft; Shaimaa Yassin (2018): "Comparing Retrospective and Panel Data Collection Methods to Assess Labor Market Dynamics." IZA Journal of Development and Migration 8(17), 1-34.

Assaad, Ragui; Rania Roushdy (2009): "Methodological Appendix 3: An Analysis of Sample Attrition in the Egypt Labor Market Panel Survey 2006,” in: Assaad, Ragui (ed.), The Egyptian Labor Market Revisited. Cairo, Egypt: American University in Cairo Press, 303-316.

Assaad, Ragui; Mohamed Saleh (2018): "Does Improved Local Supply of Schooling Enhance Intergenerational Mobility in Education? Evidence from Jordan.” World Bank Economic Review 3(1), 633-655.

Assaad, Ragui; Colette Salemi (2019): "The Structure of Employment and Job Creation in Jordan: 2010-2016." in: Krafft, Caroline; Ragui Assaad (eds.), The Jordanian Labor Market Between Fragility and Resilience. Oxford, UK: Oxford University Press, 27-51.

Azzeh, Laila (2017): “Unemployment at Highest Rate in 25 Years - DoS.” Jordan Times (June 2).

Beegle, Kathleen; Joachim de Weerdt; Stefan Dercon (2011): "Migration and Economic Mobility in Tanzania: Evidence from a Tracking Survey." Review of Economics and Statistics 93(3), 1010-1033.

Brunette, Waylon; Samuel Sudar; Mitchell Sundt; Clarice Larson; Jeffrey Beorse; Richard Anderson (2017): "Open Data Kit 2.0: A Services-Based Application Framework for Disconnected Data Management." MobiSys 2017 - Proceedings of the 15th Annual International Conference on Mobile Systems, Applications, and Services, Niagara Falls, NY.

Department of Statistics (Jordan) (2015a): "Table 3.5: Distribution of Population by Population Category, Sex, Nationality, Age in Single Years and Governorate." Population and Housing Census 2015. http://www.dos. gov.jo/dos_home_a/main/population/census2015/Persons/Persons_3.5.pdf. Accessed 1 October 2017.

Department of Statistics (Jordan) (2015b): "Table 8.1: Distribution of Non-Jordanian Population Living in Jordan by Sex, Nationality, Urban/Rural and Governorate.” Population and Housing Census 2015. http:// www.dos.gov.jo/dos_home_a/main/population/census2015/Non-Jordanians/Non-jordanian_8.1.pdf. Accessed 3 November 2017.

Department of Statistics (Jordan) (2015c): "Table 2.29: Distribution of Private Households and Members by Sex, Age Groups, and Nationality of Head of Household and Governorate." http://www.dos.gov.jo/dos_ home_a/main/population/census2015/HousingUnits/Housing_2.29.pdf. Accessed 9 February 2018.

Department of Statistics (Jordan) (2015d): "Table 2.25: Distribution of Private Households by Number of Household Members, Urban/Rural and Governorate." Population and Housing Census 2015. http://www. dos.gov.jo/dos_home_a/main/population/census2015/HousingUnits/Housing_2.25.pdf. Accessed 26 April 2018.

Department of Statistics (Jordan) (2015e): "Table 3.17: Distribution of Jordanian Population Living in Jordan Aged (13 Years and above) by Marital Status, Age Groups, Sex and Governorate.” Population and Housing Census 2015. http://www.dos.gov.jo/dos_home_a/main/population/census2015/Persons/Persons_3.17. pdf. Accessed 22 April 2018.

Department of Statistics (Jordan) (2015f): "Population \& Housing Census, 2015 Enumeration Questionnaire, Enumeration Stage." Population and Housing Census 2015. http://www.dos.gov.jo/dos_home_e/main/ population/census2015/Questionare_en.pdf. Accessed 26 April 2018.

Department of Statistics (Jordan) (2015g): "Table 5.9: Distribution of Jordanian Population Living in Jordan Aged (15 Years and above) by Economic Activity Status, Age Groups, Sex and Governorate." Population and Housing Census 2015. http://www.dos.gov.jo/dos_home_a/main/population/census2015/WorkForce/WorkingForce_5.9.pdf. Accessed 1 October 2017.

Department of Statistics (Jordan) (2017): "Table 2.6: Population Age 15+ Years by Economic Activity Status, Sex, Broad Age Groups \& Nationality (Percentage Distribution). First Round -2017.” Employment and Unemployment Survey. http://www.dos.gov.jo/owa-user/owa/emp_unemp.show_tables1?lang=E\&year1=2017\&round=1\&t_no=18. Accessed 26 April 2018.

Department of Statistics (Jordan) (2021): “Employment and Unemployment." http://www.dos.gov.jo/dos home_e/main/linked-html/Emp\&Un.htm. Accessed 18 May 2021. 
Economic Research Forum, and UN Women (2020): "Progress of Women in the Arab States 2020: The Role of the Care Economy in Promoting Gender Equality." Cairo, Egypt: UN Women.

Elbadawy, Asmaa (2015): "Education in Egypt: Improvements in Attainment, Problems with Quality and Inequality." in: Assaad, Ragui; Caroline Krafft (eds.), The Egyptian Labor Market in an Era of Revolution. Oxford, UK: Oxford University Press, 127-146.

El-Hamidi, Fatma; Mona Said (2014): "Gender-Based Wage and Occupational Inequality in the New Millenium in Egypt." The Journal of Developing Areas 48(1), 21-41.

El-Mallakh, Nelly; Jackline Wahba (2018): "Syrian Refugees and the Migration Dynamics of Jordanians: Moving in or Moving Out?” Economic Research Forum Working Paper Series No. 1191. Cairo, Egypt.

Fallah, Belal; Caroline Krafft; Jackline Wahba (2019): "The Impact of Refugees on Employment and Wages in Jordan.” Journal of Development Economics 139, 203-216.

Friedrich, Carmen; Henriette Engelhardt; Florian Schulz (2020): "Women's Agency in Egypt, Jordan, and Tunisia: The Role of Parenthood and Education." Population Research and Policy Review 1-34, https://doi.org/10.1007/s11113-020-09622-7.

Gebel, Michael; Stefanie Heyne (2016): "Delayed Transitions in Times of Increasing Uncertainty: School-toWork Transition and the Delay of First Marriage in Jordan." Research in Social Stratification and Mobility 46(A), 37-49.

Hailat, Mahmoud (2019): "Education of Jordanians: Outcomes in a Challenging Environment," in: Krafft, Caroline; Ragui Assaad (eds.), The Jordanian Labor Market Between Fragility and Resilience. Oxford, UK: Oxford University Press, 203-224.

Hendy, Rana (2015): “Women's Participation in the Egyptian Labor Market: 1998-2012," in: Assaad, Ragui; Caroline Krafft (eds.), The Egyptian Labor Market in an Era of Revolution. Oxford, UK: Oxford University Press, 147-161.

Himelein, Kristen (2014): "Weight Calculations for Panel Surveys with Subsampling and Split-off Tracking." Statistics and Public Policy 1(1), 40-45.

Hlasny, Vladimirl; Paolo Verme (2018): "Top Incomes and the Measurement of Inequality in Egypt." World Bank Economic Review 32(2), 428-455.

Krafft, Caroline (2020): "Why Is Fertility on the Rise in Egypt? The Role of Women's Employment Opportunities." Journal of Population Economics 33(4), 1173-1218.

Krafft, Caroline; Ragui Assaad (ed.) (2019): The Jordanian Labor Market Between Fragility and Resilience. Oxford, UK: Oxford University Press.

Krafft, Caroline; Ragui Assaad (2020): “Employment's Role in Enabling and Constraining Marriage in the Middle East and North Africa." Demography 57, 2297-2325.

Krafft, Caroline; Ragui Assaad; Khandker Wahedur Rahman (2019): "Introducing the Egypt Labor Market Panel Survey 2018." Economic Research Forum Working Paper Series No. 1360. Cairo, Egypt.

Krafft, Caroline; Zea Branson; Taylor Flak (2021): "What's the Value of a Degree? Returns to Education in Egypt, Jordan, and Tunisia." Compare: A Journal of Comparative and International Education 51(1), 61-80.

Krafft, Caroline; Caitlyn Keo; Luca Fedi (2019): "Rural Women in Egypt: Opportunities and Vulnerabilities." Economic Research Forum Working Paper Series No. 1359. Cairo, Egypt.

Krafft, Caroline; Susan Razzaz; Caitlyn Keo; Ragui Assaad (2019): "The Number and Characteristics of Syrians in Jordan: A Multi-Source Analysis," in: Krafft, Caroline; Ragui Assaad (eds.), The Jordanian Labor Market Between Fragility and Resilience. Oxford, UK: Oxford University Press, 173-199.

Krafft, Caroline; Maia Sieverding (2018): “Jordan's Fertility Stall and Resumed Decline: An Investigation of Demographic Factors.” Economic Research Forum Working Paper Series No. 1193. Cairo, Egypt.

Krafft, Caroline; Maia Sieverding; Colette Salemi; Caitlyn Keo (2019): "Syrian Refugees in Jordan: Demographics, Livelihoods, Education, and Health,” in: Krafft, Caroline; Ragui Assaad (eds.), The Jordanian Labor Market Between Fragility and Resilience. Oxford, UK: Oxford University Press, 141-172.

Lenner, Katharina; Lewis Turner (2019): "Making Refugees Work? The Politics of Integrating Syrian Refugees into the Labor Market in Jordan." Middle East Critique 28(1), 65-95.

Magablih, Khalid M.A.; Mairna Hussein Mustafa (2018): "How the 'Arab Spring' Influenced Tourism and Hospitality Industry in Jordan: Perceptions of Workers in Tourism and Hospitality Business." Journal of Tourism and Hospitality Management 6(2), 132-139.

Malaeb, Bilal; Jackline Wahba (2018): "Impact of Refugees on Immigrants' Labor Market Outcomes." Economic Research Forum Working Paper Series No. 1194. Cairo, Egypt, Egypt.

Malaeb, Bilal; Jackline Wahba (2019): "Migration Dynamics during the Refugee Influx in Jordan," in: Krafft, Caroline; Ragui Assaad (eds.), The Jordanian Labor Market Between Fragility and Resilience. Oxford, UK: Oxford University Press, 125-140. 
Maystadt, Jean-François; Kalle Hirvonen; Athur Mabiso; Joachim Vandercasteelen (2019): "Impacts of Hosting Forced Migrants in Poor Countries.” Annual Review of Resource Economics 11(1), 439-459.

Ministry of Labor, and Ministry of Planning and International Cooperation. (2012): "Jordan's National Employment Strategy 2011-2020." Amman, Jordan.

Said, Mona (2015): "Wages and Inequality in the Egyptian Labor Market in an Era of Financial Crisis and Revolution," in: Assaad, Ragui; Caroline Krafft (eds.), The Egyptian Labor Market in an Era of Revolution. Oxford, UK: Oxford University Press, 52-69.

Salehi-Isfahani, Djavad; Insan Tunali; Ragui Assaad (2009): "A Comparative Study of Returns To Education of Urban Men in Egypt, Iran, and Turkey." Middle East Development Journal 1(2), 145-187.

Selwaness, Irene; Caroline Krafft (2021): "The Dynamics of Family Formation and Women's Work: What Facilitates and Hinders Female Employment in the Middle East and North Africa?" Population Research and Policy Review 40, 533-587.

Sieverding, Maia; Nasma Berri; Sawsan Abdulrahim (2019): "Marriage and Fertility Patterns among Jordanians and Syrian Refugees in Jordan," in: Krafft, Caroline; Ragui Assaad (eds.). The Jordanian Labor Market: Between Fragility and Resilience. Oxford, UK: Oxford University Press, 259-288.

Sieverding, Maia; Caroline Krafft; Nasma Berri; Caitlyn Keo (2020): "Persistence and Change in Marriage Practices among Syrian Refugees in Jordan." Studies in Family Planning 51(3), 225-249.

Sieverding, Maia; Caroline Krafft; Nasma Berri; Caitlyn Keo; Mariam Sharpless (2018): "Education Interrupted: Enrollment, Attainment, and Dropout of Syrian Refugees in Jordan." Economic Research Forum Working Paper Series No. 1261. Cairo, Egypt.

Thomas, Duncan; Firman Witoelar; Elizabeth Frankenberg; Bondan Sikoki; John Strauss; Cecep Sumantri; Wayan Suriastini (2012): "Cutting the Costs of Attrition: Results from the Indonesia Family Life Survey." Journal of Development Economics 98(1), 108-123.

Turner, Lewis (2016): "Explaining the (Non-) Encampment of Syrian Refugees: Security, Class and the Labour Market in Lebanon and Jordan." Mediterranean Politics 20(3), 386-404.

UNHCR (2017): "Syria Regional Refugee Response - Jordan." http://data.unhcr.org/syrianrefugees/country. php?id=107. Accessed 18 October 2017.

UNHCR (2018): "Situation Syria Regional Refugee Response." https://data2.unhcr.org/en/situations/syria/ location/36. Accessed 17 March 2018.

Vaillant, Julia (2013): "Attrition and Follow-up Rules in Panel Surveys: Insights from a Tracking Experience in Madagascar." Review of Income and Wealth 59(3), 509-538.

Wahba, Jackline (2015): "Through the Keyhole: International Migration in Egypt," in: Assaad, Ragui; Caroline Krafft (eds.), The Egyptian Labor Market in an Era of Revolution. Oxford, UK: Oxford University Press, 198-217. 